\title{
Fundamentals and current strategies for Peripheral Nerve Repair and Regeneration
}

\author{
Cristiana R. Carvalho ${ }^{\mathrm{a}, \mathrm{b}, \mathrm{c}}$, Rui L. Reis ${ }^{\mathrm{a}, \mathrm{b}, \mathrm{c}}$ and Joaquim M. Oliveira ${ }^{\mathrm{a}, \mathrm{b}, \mathrm{c}}$
}

\begin{abstract}
A body of evidence indicates that peripheral nerves have an extraordinary yet limited capacity to regenerate after an injury. Peripheral nerve injuries have confounded professionals in this field, from neuroscientists to neurologists, plastic surgeons, and the scientific community. Despite all the efforts, full functional recovery is still seldom. The inadequate results attained with the "gold standard" autograft procedure still encourage a dynamic and energetic research around the world for establishing good performing tissue engineered alternative grafts. Resourcing to nerve guidance conduits, a variety of methods have been experimentally used to bridge peripheral nerve gaps of limited size, up to 30-40 mm in length, in humans. Herein, we aim to summarize the fundamentals related to peripheral nerve anatomy and overview the challenges and scientific evidences related to peripheral nerve injury and repair mechanisms. The most relevant reports dealing with the use of both synthetic and naturalbased biomaterials used in tissue engineering strategies when treatment of nerve injuries is envisioned are also discussed in depth, along with the state-of-the-art approaches in this field.
\end{abstract}

Keywords: Peripheral Nerve Regeneration, Tissue Engineering, Biomaterials 


\section{INTRODUCTION}

The most significant advances in peripheral nerve repair and regeneration have been achieved over the last years with the improvement of technological tools. However, the study of nerve and its regenerative potential initiated in earlier times, possibly in the ancient Greek period [1]. Nevertheless, the establishment of the basic notions and modern concepts of nerve repair and regeneration were only developed in the twentieth century with the emergence of the neurosurgery field [2].

Peripheral nerve injuries (PNIs) usually involve sensory and motor neurons and frequently result in axonal loss and demyelination, depending on the severity of the injury. Under ideal conditions, regeneration of a nerve cable is followed by remyelination, thus allowing a certain degree of sensory and functional recovery to be achieved. In the clinics, PNIs repair is based on the knowledge of physiological regenerative processes [3]. However, if no additional strategies are used, functional recovery following an injury remains incomplete. In order to address this tissue regeneration and improve clinical outcomes, the contribution of multidisciplinary fields is required. Interestingly, tissue engineering (TE) has allowed to take impressive steps towards the improvement of functional outcomes, by means of combining areas such as reconstructive microsurgery, transplantation and biomaterials [4]. Furthermore, the basic triad of TE has an important role in successful nerve regeneration, as the goal remains to develop and fabricate novel nerve guidance conduits (NGCs) built from a particular biomaterial, capable of housing cells and deliver biological and physical molecular cues, enhancing and guiding nerve regeneration [5]. As tubulization and the use of NGCs remains the base for nerve repair, the choice of adequate type(s) of biomaterials is the pillar to achieve the so desired regeneration [6]. In fact, it has been confirmed experimentally that engineered NGCs may also lead to effective nerve repair, that was earlier thought to only be restorable using autograft [7].

The topics related to the anatomy of the nervous system as well as on the innate mechanisms related to the natural attempts of tissue regeneration are addressed herein. A comprehensive overview of the biomaterial's approaches being pursuit in nerve regeneration can also be found. Pre-clinical studies comprising natural, synthetic and endogenous biomaterials have also been extensively explored. Additionally, strategies to achieve nerve repair as well as challenges that need to be overcome are highlighted. 


\subsection{Organization of the Nervous System}

In the case of an injury, in order to make an initial assessment/diagnosis and proceed with the appropriate treatment, it is imperative to have plain knowledge of nervous system anatomy. The nervous system is the instrument through which organized vertebrates keep in touch with its internal structures and external surroundings, reacting to changes and adapting to them. This system has a fundamental role in behavior control and can be divided in the central nervous system (CNS) and peripheral nervous system (PNS) [8]. The CNS, composed of the brain and its caudal prolongation, the spinal cord, is connected to the periphery by the PNS [9]. During the embryonic development known as ontogenesis, the CNS emerges from the neural plate of the ectoderm that molds into the neural groove, from which the neural tube results. Subsequently, the neural tube is restructured and gives origin to brain and spinal cord. This phenomenon is known as neurulation. Two bands of tissue called the neural crest will give origin to the forthcoming PNS that run along the neural tube. These are multi-potent progenitor cells that later form the PNS [10].

At an anatomical level, the CNS consists of the brain and the spinal cord, being both enclosed by three types of meninges [11]. The PNS consists of cranial nerves, spinal nerves and their roots and branches, peripheral nerves, and neuromuscular junctions, in a total of 43 pairs of sensory and motor nerves [12]. Bundles of axons in the PNS are referred to as nerves. These are composed of more than just nervous tissue. They have connective tissue participating in their structure, as well as blood vessels supplying the tissues with nourishment. A neuron consists of a cell body, known as Soma, which gives out extensions in PNS, called axons. These are crucial for targeting distant tissues and organs. Axons are coated with myelin sheath membranes, formed by Schwann cells.

Anatomically, each individual axon is firstly protected by a myelin sheath and sheltered by a first layer of collagen and elastic elements, the endoneurium. A group of endoneurium protects axon groups into nerve fascicles, which are sheathed by the perineurium, mainly composed of connective tissue. Finally, several fascicles are gathered together by the epineurium. In the outer layer, the mesoneurium can be found, which also comprises blood vessels supplying oxygen and nutrients to the nerve. Any break or defect in this stratified structure fallouts in a programmed and permanent cell death, unless rapidly and meticulously reestablished [13]. Besides myelinated nerve fibers, the PNS contains unmyelinated fibers, with the majority found in the cutaneous nerve, the dorsal roots, and some muscle nerves. Fig. 1 
shows the schematic representation of CNS and PNS in the human body, as well as detailed anatomy of peripheral nerves and neurons.

Myelin is a constant in both PNS and CNS. Myelin found on neurons in the PNS is formed by Schwann cells while myelin found in the CNS is generated by oligodendrocytes. However, one striking difference can be pointed. In one hand, oligodendrocytes and Schwann cells are often compared to each other in terms of function. However, the biggest difference among the two resides in their ability to repair neurons after nerve damage, as Schwann cells promote nerve regeneration and repair, whereas oligodendrocytes inhibit neuron repair after an injury [14].

In terms of purpose, the primary function of the CNS is integration. Conversely, the PNS is mainly a receptor and effector organ that connects the CNS to every part of the body by cranial and spinal nerves, and associated ganglia. This connection is made by sensory and motor neurons that conduct impulses to the CNS or the periphery, respectively [15].

\subsection{General Overview of Peripheral Nerve Injuries}

Neurological defects are among the most demanding clinical situations despite decades of research in the neurological field [16]. The reason for this relies in the complexity of the nervous system functions, structure and anatomy, which makes it more challenging to treat as compared to other tissues in the human body [17]. Opposing to the CNS, the PNS is not protected by a hard bone layer or by the blood-brain barrier, making it much more disposed to traumatisms or any kind of injuries [18]. Therefore, PNIs are considered a huge clinical burden, being the incidence 1 in 1,000 individuals per year [19]. The estimated numbers of PNIs range from 300,000 and 360,000 cases per year for Europe and the USA, respectively [20]. In fact, PNIs are associated to $\$ 150$ billion health-care expenses per year in the USA alone [15]. These costs are underestimated, since "bed-days" and lack of productivity also account for monetary losses, worldwide. It has been assessed that $25 \%$ of patients suffering from traumatic injuries and undergo surgery do not return to work 1.5 years after the intervention. 


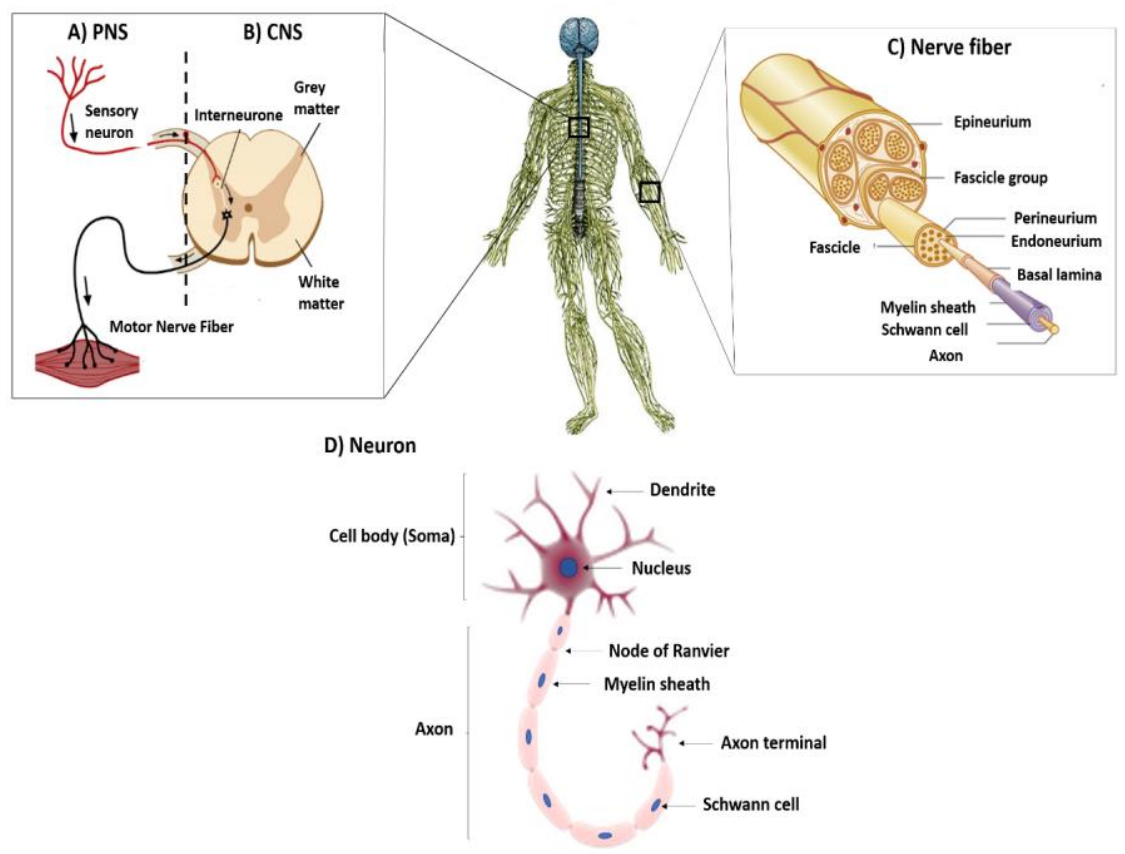

Fig. 1 - Schematic representation of nervous system anatomy in the human body. The nervous system is divided in CNS (in blue) and PNS (green). A) The PNS is composed of several pairs of nerves, which transmit signals between afferent sensory neurons and efferent motor neurons to the CNS; B) CNS, composed of the brain and spinal cord, which has connections to PNS. In CNS, interneurons receive information from the periphery; C) A peripheral nerve contains many nerve fibers that are held together by connective tissue and bundled into nerve fascicles. The entire nerve is enclosed by connective tissue called epineurium. Individual fascicles are delineated by perineurium. Endoneurium surrounds each nerve fiber; and D) Each neuron is composed of a cell body, known as Soma, which contains dendrites. The axon, elongating from the cell body may present myelin sheaths. The spaces between the myelin sheaths are Nodes of Ranvier. In the end of the neuron there is an axon terminal, which releases neurotransmitters from one neuron to another.

This scenario tends to worsen with the increasing world population and respective average lifespan. Considering those, an additional number of injuries tend to appear and consequently a high number of treatments and surgeries will be required to allow the restoration of the damaged nerves [21]. Although the CNS is vastly protected and therefore less prone to injuries, it has a limited ability to regenerate because of the succeeding scar tissue development which can be created by a vast range of cell types, such as fibroblasts, neuroglia, monocytes, and endothelial cells [22]. In contrast, PNIs are considerably more common, but the peripheral nerves have a greater regeneration potential as compared to the nerves of CNS. This is because PNS glial cells, Schwann cells, adjust to a regenerative phenotype and have the capacity of triggering neuronal regenerative processes, although usually slow and in a partial manner [23]. The regeneration process, however, is dependent on certain factors, such as the lesion size and the quality of the affected nerve, the person's health statues (e.g. diabetic or non-diabetic), age, and most importantly, the time period from injury to surgical reconstruction. In the case of lengthy time without repair, the distal nerve end and target tissues and organs are chronically 
denervated, becoming chronically axotomized, which leads to neurons undergoing apoptosis [24].

Given to their exposure, peripheral nerve damages can be caused by many types of events, such as traumatic injuries, complications on surgeries, congenital defects and war wounds. Concerning the traumatic injuries, they can also vary significantly and include tearing injuries, crushing or smashing, ischemia, and less prevalent types of injury such as thermal, electric shock and radiation [25]. Compression neuropathies are also ubiquitous among nerve injuries. For instance, carpal tunnel syndrome, the most common compression type of injury, affects $4 \%$ of the overall population [26]. A vast range of diseases can also be the root cause of PNIs, as is the case of diabetic peripheral neuropathies [27, 28]. Most of these traumatic events cause neuronal death, demyelination, and axonal degeneration resulting in persistent complaints, such as impaired sensory and motor nerve functionality and radiating neuropathic pain. Disorders concerning the PNS usually have overwhelming and life-disturbing impacts on patients' daily functions and habits, which are not usually regarded as significant. There is a substantial lack of consideration of the impact of injury on social and emotional wellbeing, despite their importance to patients. There is, in fact, a strong correlation between PNIs and pain and depression in those patients [29].

Due to the great variety of peripheral nerve traumas, there was a categorization of nerve injuries in main domains, as an attempt to systematize them for the medical and scientific community. Several degrees of injury to peripheral nerves are detailed in Table 1, which were firstly described by Seddon [30], and later by Sunderland [31].

Table 1 - Seddon [30] and Sunderland [31] classification of PNIs.

\begin{tabular}{|c|c|c|c|c|}
\hline $\begin{array}{l}\text { Seddon and } \\
\text { Sunderland } \\
\text { classification } \\
\end{array}$ & Process & $\begin{array}{c}\text { Sunderland } \\
\text { scheme of } \\
\text { nerve injury }\end{array}$ & $\begin{array}{c}\text { Neurological } \\
\text { deficits }\end{array}$ & Degree of recovery \\
\hline $\begin{array}{c}\text { Neurapraxia } \\
\text { I }\end{array}$ & $\begin{array}{l}\text { Local myelin damage } \\
\text { usually secondary to } \\
\text { compression }\end{array}$ & & $\begin{array}{l}\text { Neuritis, } \\
\text { paresthesia }\end{array}$ & Full recovery \\
\hline \multirow[t]{2}{*}{$\begin{array}{l}\text { Axonotmesis } \\
\text { II, III, IV }\end{array}$} & $\begin{array}{c}\text { Axon severed but } \\
\text { endoneurium intact } \\
\text { (optimal circumstances } \\
\text { for regeneration) }\end{array}$ & & Paresthesia & Full recovery \\
\hline & $\begin{array}{c}\text { Axon discontinuity, } \\
\text { endoneurial tube } \\
\text { discontinuity, }\end{array}$ & & $\begin{array}{l}\text { Paresthesia, } \\
\text { dysesthesia }\end{array}$ & $\begin{array}{c}\text { Wallerian } \\
\text { degeneration, } \\
\text { recovery incomplete }\end{array}$ \\
\hline
\end{tabular}




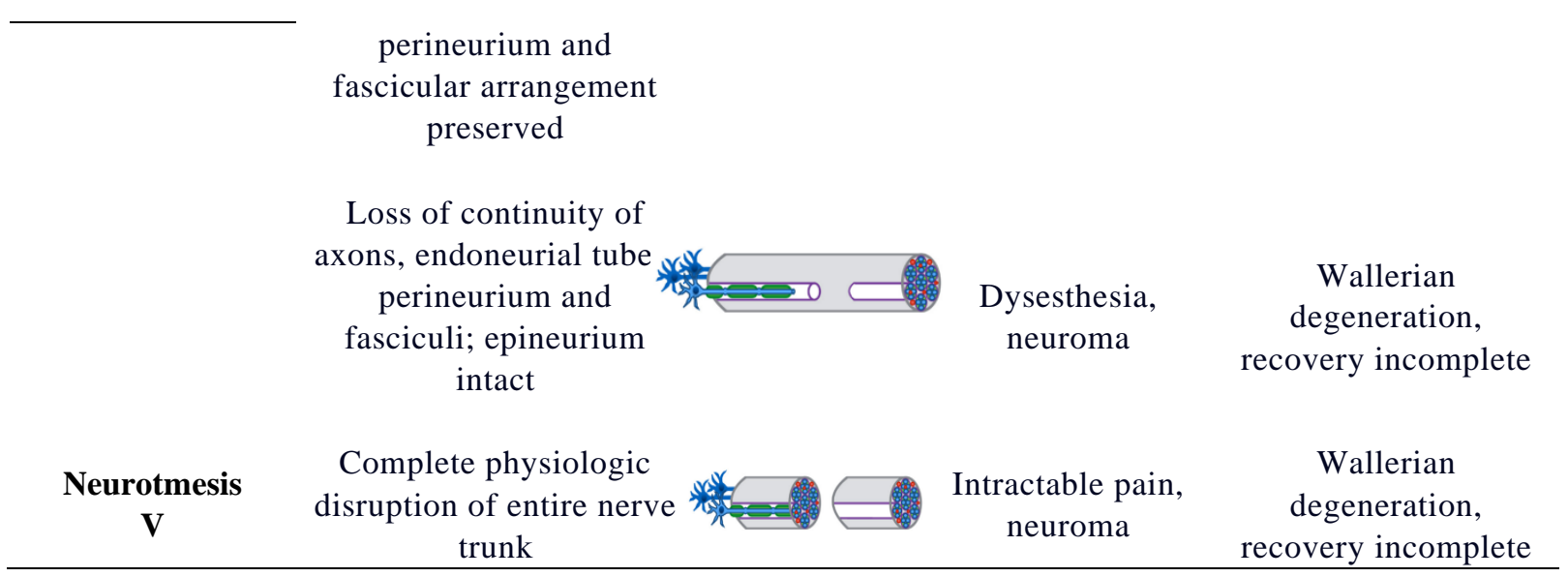

The Seddon classification is divided into three categories according to the gravity of the injury: i) neurapraxia, ii) axonotmesis, and iii) neurotmesis. By its turn, Sunderland classification comprises five different categories: first, second, third, fourth and fifth degree. Seddon classification is more straightforward and therefore the most used. Neurapraxia is the least severe type of injury and it is not associated with long-term impairments and consequences. The second level, axonotmesis, is related to axon and myelin discontinuity or disruption. The most severe type, neurotmesis, involves the complete disconnection of the nerve, where a gap is formed.

\subsection{Degeneration and Regeneration processes following PNIs}

Immediately after injury, the regeneration process of peripheral nerves runs in sequenced phases and different events occur at different levels on the injury site encompassing both proximal and distal sites (Fig. 2A) [32]. In the proximal position, separated axons and cell bodies degenerate via a programmed cell death pathway called chromatolysis [33]. In the distal injury end, a process called Wallerian degeneration occurs 24 to 48 hours after injury and all nerve components, including the distal axons and adjacent myelin starts to degenerate [34]. The goal of that phenomenon is related to the clearance of undesired debris. Schwann cells phagocytize axonal and myelin debris, until only empty endoneurial tubes remain. Normal nerve function depends on such type of cells, which are the myelinating glial cells of the PNS $[35,36]$.

After debris removal, Schwann cells fill the empty endoneurial tubes and organize in characteristic bands or tubes of Bungner, and by this mean supporting the re-growth of axons. Not only Schwann cells have a crucial role, but also macrophages are recruited to the area 
releasing growth factors and cytokines. The release of cytokines will stimulate Schwann cells and fibroblast proliferation and are responsible for the axonal regeneration process [37]. Ahead in the process, in the proximal injury end, a growth cone emerges following the path formed by the band of Bungner, which is of fundamental importance for the advance of the regenerating axon [38]. The growth cone can be seen in Fig. 2B [39]. In optimal conditions, axonal regeneration is very slow, occurring at a rate of approximately $1 \mathrm{~mm} /$ day and demanding at least more than one year for muscle re-innervation and initial functional recovery [40]. 

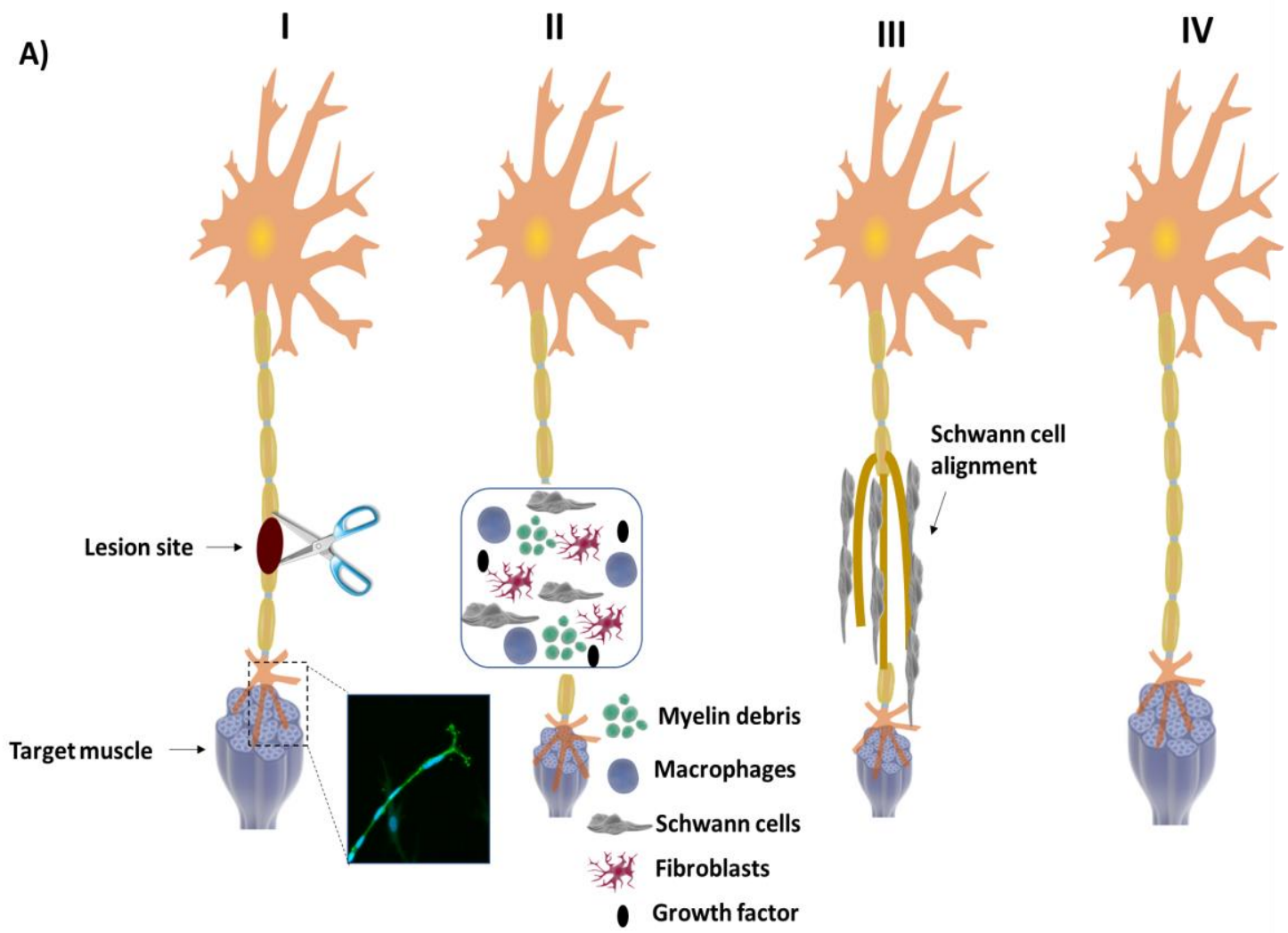

B)

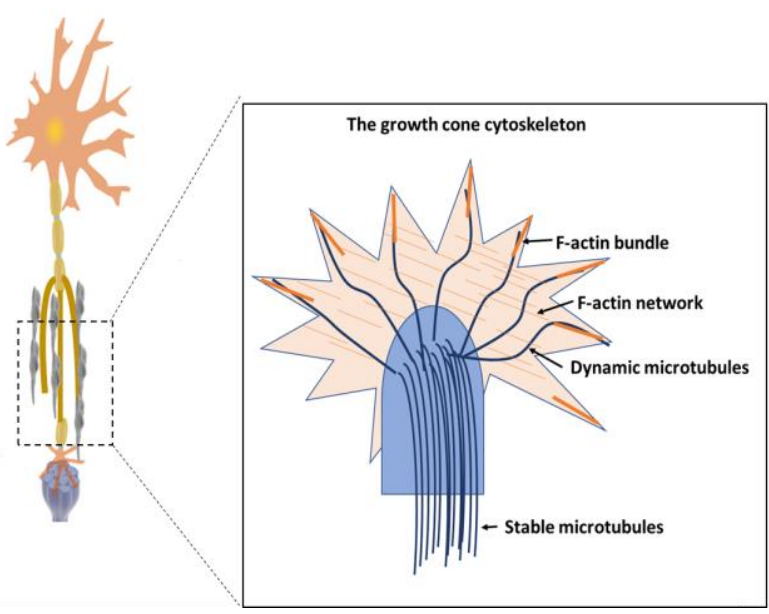

Fig. 2 - A) Progression of Wallerian Degeneration: I) A single axon with enwrapping myelinating Schwann cells suffers a traumatic injury; II) The axon breaks and the distal stump undergoes cellular changes. Distal to the injury, there is a destruction of the remaining intact axon and disintegration of myelin cover, leaving debris behind. Macrophages and Schwann cells, which turned to a pro-regenerative phenotype, accumulate at the lesion site and scavenge the debris; III) Schwann cells aligns in the Bands of Bungner. These tubes provide a permissive growth environment and guide extending axons towards distal targets; IV) If the axon is able to traverse the injury gap, the distal target becomes re-enervated and the neuron becomes fully functional; and B) The growth cone is a large actin-supported extension of a regenerating neurite pursuing its corresponding synaptic target. It is responsible for the migration and path finding during neurite extension, in which the lamellipodia and filopodia interact with the adjacent matrix.

After debris removal, Schwann cells fill the empty endoneurial tubes and organize in characteristic bands or tubes of Bungner, and by this mean supporting the re-growth of axons. 
Not only Schwann cells have a crucial role, but also macrophages are recruited to the area releasing growth factors and cytokines. The release of cytokines will stimulate Schwann cells and fibroblast proliferation and are responsible for the axonal regeneration process [37]. Ahead in the process, in the proximal injury end, a growth cone emerges following the path formed by the band of Bungner, which is of fundamental importance for the advance of the regenerating axon [38]. The growth cone can be seen in Fig. 2B [39]. In optimal conditions, axonal regeneration is very slow, occurring at a rate of approximately $1 \mathrm{~mm} /$ day and demanding at least more than one year for muscle re-innervation and initial functional recovery [40].

\subsubsection{The role of Schwann cells in injury response}

Schwann cells are among the first active components after nerve injury. Finding their embryologic origin in the neural crest, Schwann cells have the capacity to proliferate, produce and deliver neurotrophic factors, modulate the immune response, myelinate axons, migrate and adjust their shape and phenotype. This makes them the perfect cells towards intervening in neural repair [41].

Although the degeneration of axons in the distal nerve end starts roughly 2 days after injury, activity of Schwann cells can be distinguished before that, within hours of injury, where Schwann cells undergo a phenotypic change [14]. This phenotypic change will support PNR in several ways. Firstly, they dedifferentiate by means of acquiring a non-myelinating and immature Schwann cells stage phenotype. That stage is characterized by an up-regulation of L1, NCAM, p75NTR, and glial fibrillary acidic protein (GFAP). On the other hand, myelinassociated genes are down-regulated, which comprise myelin transcription factor Egr2, organizational and mechanical supporting proteins as such as Protein 0 (P0), myelin basic protein (MBP) and myelin associated glycoprotein [42]. There is also an up-regulation and secretion of a beneficial group of trophic factors, such as nerve growth factor (NGF), brainderived neurotrophic factor (BDNF), ciliary neurotrophic factor (CNTF), basic fibroblast growth factor (bFGF), vascular endothelial growth factor (VEGF) and pleiotrophin [43]. Furthermore, the expression of cytokines capable of recruiting macrophages is also upregulated, which include tumor necrosis factor (TNF)- $\alpha$, LIF, interleukin (IL)-1 $\alpha$, IL-1 $\beta$, and monocyte chemoattractant protein 1 (MCP-1). Schwann cells activate a cell-intrinsic myelin breakdown process, which will destroy myelin by an autophagy process, roughly at the $5^{\text {th }}$ day 
after injury [23]. This is a key process intimately related to increasing the regenerative potential after injury. In fact, elimination of degenerated myelin is fundamental for repair since PNS myelin holds molecules that inhibit regeneration of severed axons, namely the myelin associated glycoprotein [44]. At last, Schwann cells response to injury also includes the formation of regeneration tracks, known as Bands of Bungner. For that, Schwann cells adopt the elongated spindle-shape morphology and line up in columns. To perform such task, they express a variety of adhesion molecules on their surface, such as N-cadherin, L1 and N-CAM. Extracellular matrix (ECM) molecules are also secreted, such as laminin and fibronectin. All the secreted molecules are considered guidance-promoting signaling molecules, important not only during early development, but also to create a microenvironment that mediates axon regrowth and guidance, allowing axons to reconnect with their target tissues [45].

Overall, Schwann cells acquire a pro-regenerative phenotype, capable of promoting nerve repair, when there is a conversion of myelin-Schwann cells to repair-Schwann cells. The single protein capable of this transformation is c-Jun, which is rapidly up-regulated in the distal nerve end Schwann cells after injury [46].

\subsection{Strategies for Nerve repair}

Clinically, the straight-forward technique to repair minor nerve defects is the end-to-end suture [47]. However, this technique is circumscribed to a maximum gap length ranging from $5 \mathrm{~mm}$ to $20 \mathrm{~mm}$, depending on the nerve, since the suture must be done without creating excessive tension in the nerve ends. When the nerve gap length makes end-to-end suture unfeasible, peripheral nerve grafts are the gold standard treatment for nerve restoration. In a technique that dates to Philipeux and Vulpian in 1817 [48], the insertion of a graft section provides a physical and biological scaffolding, over which axonal outgrowth occurs. Grafts can be autologous, known as autografts, or allografts. The use of autografts has inherent disadvantages, such as donor site morbidity and reduced availability [49]. For allografts, the tissue is harvested from another donor, which can increase the risk of disease transmission and immunological response. However, related to allografts, a recent and promising alternative for patients who have exhausted all reconstructive methods is the vascularized composite tissue allotransplantation (VCA) [50]. Furthermore, tacrolimus, one of the immunosuppressant drugs that will accompany the patients for a life-time when subjected to this procedure, has shown to have positive effects in PNR [51]. 
However, despite those seemingly good chances of recovery with grafts, incomplete recuperation from PNIs usually can lead to multiple negative consequences, which comprise numbness of affected members, chronic pain, diminishing of sensory and/or motor function and a disturbing permanent disability of the patients [52]. It is a fact that these outcomes are unsatisfactory for the demands of today's patient lives, since only $25 \%$ of patients regain proper motor function, and less than $3 \%$ recuperate sensation in a full extent [53].

Decellularized nerve conduits are another possibility for nerve repair [54]. In order to avoid the need of immunosuppressive drugs associated to allografts requirements, which make the patient more prone to acquire infection and tumors, the decellularized nerve conduits can eliminate the cellular components that cause immunogenic reactions. However, the native ECM is conserved, along with the basal lamina, the guiding mechanical cues for axonal growth is maintained. Several methods can be used to decellularize nerves, among them, physical methods such as lyophilization [55], direct pressure, and agitation [56]. Chemical methods have also been attempted and include digestion with alkaline or acidic solutions [57], detergents [58], together with the action of enzymes such as trypsin and endonucleases [59]. Various studies support the hypothesis that decellularized grafts are among the best options for nerve repair, since they can bridge more than 10-20 mm long gaps in rats [60, 61]. However, as concluded by the authors who performed a 10-year review of the use of allografts for PNR [54], further research is desirable in order to improve and standardize preparation protocols, including recellularization, advance their effectiveness, therefore being able to substitute the current gold standard, especially in the repair of long nerve defects.

For these reasons, increasing efforts have been made over the last decades in the search for effective alternatives to autografts. Surgical treatment strategies in the case of PNI can be seen in Fig. 3.

In an attempt to overcome the limitations of nerve grafting as well as the unsatisfactory outcomes, TE approaches focusing on the development of innovative biocompatible artificial nerve devices to assist innate regeneration processes to re-establish the peripheral nerve have also been reported $[62,63]$. TE strategies have been a widely travelled alternative to bridge the nerve gap and throughout the years many types of NGCs were proposed, being some of them already approved by the Food and Drug Administration (FDA) [64, 65]. Since mature neurons are not susceptible to mitosis phenomena, it is crucial to support the re-growth of the existing cell bodies, providing both a protective environment and guiding paths. In this way, it is 
possible to direct axons from the proximal to the distal site, permitting the proper linking of the damaged synapses connections. In brief, the protection of the injury site and performance as a guidance substrate are the two main reasons why tubulization is used in PNIs.

Engineering a NGC should aim at facilitating cellular spreading and growth of damaged nerve tissues in 3-dimensions (3D) [66]. In addition, it is crucially important that the material envisioned to be used to construct the NGC is cytocompatible and has pronounced biomechanical properties, and suturability. If an engineered NGC does not present a proper cytocompatibility, it may not contribute to the growth of damaged nerves, but would instead be the reason of acute inflammation and even infection [67]. It must exhibit good biocompatibility with low inflammatory and immunogenic reactions [68]. It must also be biodegradable, and ideally degrade in the same rate as nerve regenerates. Otherwise, a quick degradation might trigger an inflammatory response [66, 69]. Regarding the mechanical properties, the NGC should provide sufficient mechanical strength to prevent the NGC rupture during the patient's movements and physically support neural tissue regeneration. Concurrently, the NGC should have appropriate elasticity to be able to lessen tensions in the damaged area [67]. Two other major features that NGCs must possess are related to the suturability, where the suture thread cannot be pulled out of the material when in physical stress [70]. The second feature relates to the ability of a medical device to not calcify when implanted in vivo. Such characteristic must be previously tested and avoided at all costs, since calcification of a conduit would hinder regeneration in a great extent. In fact, Carvalho et al. [71] recently reported on a silk fibroin NGC that would or not calcify, according to the method of solvent removal and final surface properties.

Furthermore, the materials used to construct NGCs should prevent the penetration of fibroblasts that will lead to the formation of glial scar tissue around the implant, which could reduce the healing chances [72]. The permeability of a conduit is also an important parameter to consider in the NGC design as both nutrients and oxygen must diffuse into the site of regeneration. 


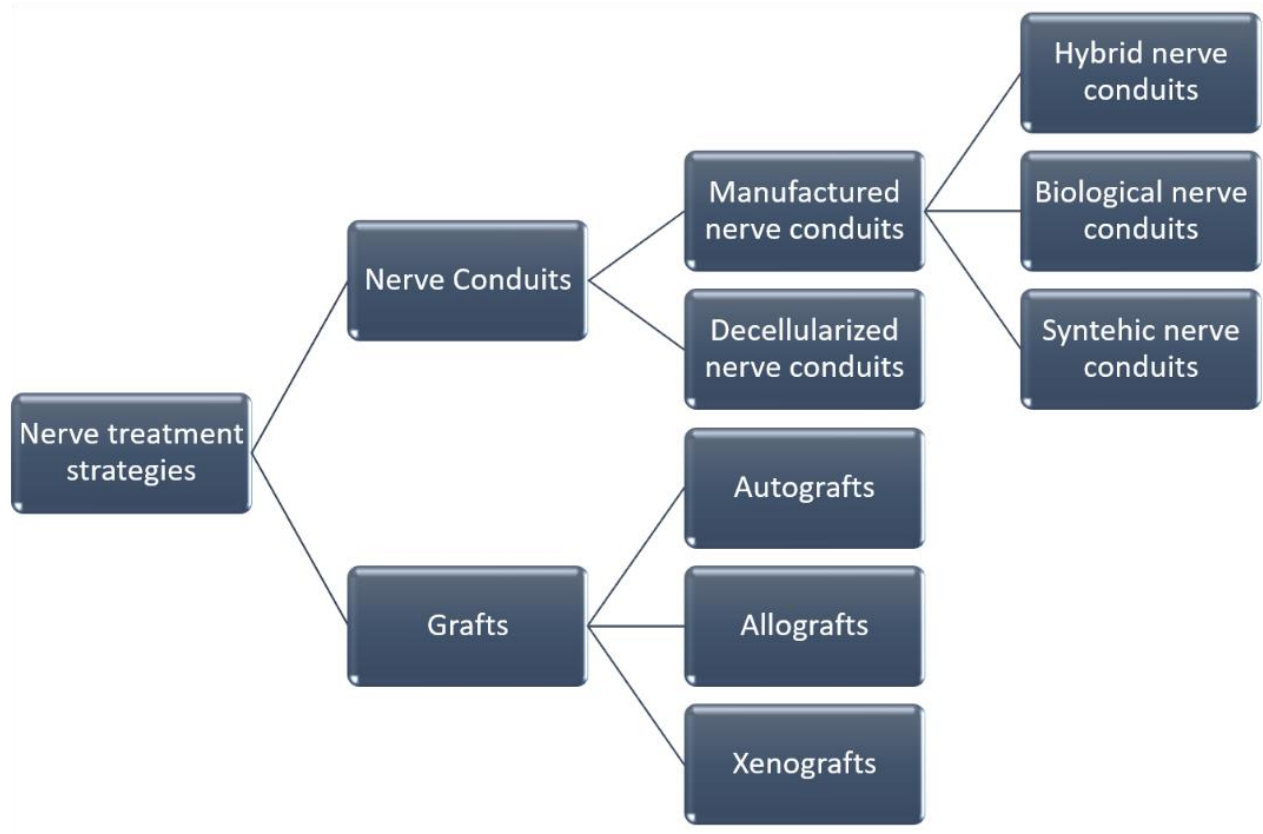

Fig. 3 - Strategies for nerve repair. In the case of a significant nerve gap formation where end-to-end coaptation is not possible, nerve grafts or engineered NGCs are required to serve as a bridge between the nerve stumps and to support axonal regrowth. In the case of grafts, they can be from the patient her/himself, known as the autografts. Allografts and xenografts are also a possibility. As an alternative, if the option falls in the NGCs, those can be nerves harvested from the body, which undergo a process of decellularization to avoid immunological reactions, maintaining the ECM for physical support. NGCs can also be manufactured and engineered with biological or synthetic materials, as well as a combination of both.

Otherwise, cells inside the conduit, especially if it is a long conduit, will be under a deleterious ischemic environment which can result in cellular hypoxia and lack of proper nutrients. Ideally, electrical conductivity would be preferred for a NGC used in neural TE in order to mimic the electrical properties of nerves and at the same time excite the neuron communication [73]. The parameters to be considered for the design of NGCs are summarized in Table 2 [74-82]. In brief, an ideal NGC should be biocompatible, biodegradable, flexible, kink-resistant, compliant, easy suturable, porous, neuroconductive and with suitable surface and overall mechanical properties [79]. Furthermore, the developed NGC should allow vascularization to occur in the lumen and avoid calcification in vivo.

Table 2 - Design criteria for the development of NGCs.

\begin{tabular}{cc}
\hline Ideal properties of NGCs & Detailed description \\
\hline Biocompatibility & Must be well incorporated in surrounding tissues and not cause \\
Degradation & inflammatory response [74]; \\
Porosity & Degradation rate should match nerve regeneration rate [75]; \\
& NGC must allow nutrient and oxygen exchange, limiting scar tissue
\end{tabular}


Anisotropy

Adequate protein release

Physical fit

Cellular support

Electrically conducting

Vascularization

Calcification

Suturability
The NGC conduit itself or the luminal filler should be aligned to provide directional guidance [77];

NGC or the luminal filler should provide sustained release of growth factors [78];

Adequate internal diameter not to compress the growing nerve [79];

Must allow the adhesion and proliferation of relevant cell types, such as

Schwann cells and endothelial cells[80];

Capable of propagating electrical signals [81];

The NGC must allow the vascularization to occur inside the NGCs, to nourish the regenerating tissue [82];

The implantable NGC must not calcify in vivo [71];

The NGC must withstand a suture being pulled out without breaking the biomaterial [83].

In the early use of NGCs made of synthetic materials, they were mainly composed by silicon tubes and could only repair injuries up to $10 \mathrm{~mm}$. Some disadvantages on the use of that conduits included total lack of biodegradability, which led to inflammation and chronic foreign body reaction, as well as lack of swelling capacity, which would compress the nerve, thus hindering the regeneration process [84]. In order to overcome such difficulties, biodegradable NGCs have been proposed, some of which are FDA-approved and being currently used in the clinical setting [65]. The FDA approved NGCs can be seen in Table 3 [65].

Table 3 - Approved NGCs used in the clinical setting.

\begin{tabular}{|c|c|c|c|}
\hline Product name & Company & $\begin{array}{l}\text { Biomaterial } \\
\text { composition }\end{array}$ & $\begin{array}{c}\text { Degradation } \\
\text { time }\end{array}$ \\
\hline Neuragen ${ }^{\circledR}$ & $\begin{array}{c}\text { Integra Neurosciences, } \mathrm{NJ}, \\
\text { USA }\end{array}$ & Collagen type I & 36-48 months \\
\hline NeuraWrap ${ }^{\mathrm{TM}}$ & $\begin{array}{c}\text { Integra Neurosciences, } \mathrm{NJ}, \\
\text { USA }\end{array}$ & Collagen type I & $36-48$ months \\
\hline Neuromend $^{\mathrm{TM}}$ & $\begin{array}{c}\text { Collagen Matrix, Inc, NJ, } \\
\text { USA }\end{array}$ & Collagen type I & 4-8 months \\
\hline Neuromatrix/Neuroflex ${ }^{\mathrm{TM}}$ & $\begin{array}{c}\text { Collagen Matrix, Inc, NJ, } \\
\text { USA }\end{array}$ & Collagen type I & 4-8 months \\
\hline Neurotube ${ }^{\circledR}$ & $\begin{array}{c}\text { Synovis Micro Companies } \\
\text { Alliance, AL, USA }\end{array}$ & $\begin{array}{l}\text { Polyglycolic acid } \\
\qquad(\text { PGA) }\end{array}$ & 6-12 months \\
\hline
\end{tabular}




\begin{tabular}{cccc} 
Neurolac $^{\mathbf{T M}}$ & Polyganics Inc, Netherlands & $\begin{array}{c}\text { Poly(D,L-lactide-co- } \varepsilon- \\
\text { caprolactone (PLCL) }\end{array}$ & 16 months \\
Salubridge/Salutunnel & Polyvinyl alcohol & Non- \\
Axoguard ${ }^{\text {TM }}$ & Salumedica LLC, GA, USA & (PVA) & degradable \\
Avance ${ }^{\circledR}$ & AxoGen Corporation, USA & Human nerve allograft & N/A \\
\hline
\end{tabular}

\subsubsection{Biomaterials}

\subsubsection{Synthetic biomaterials}

Regarding the synthetic materials, these are still considered very promising since the majority of the FDA-approved NGCs are composed of materials such as Neurotube (polyglycolide acid, PGA) and Neurolac (poly(L-lactide-co- $\varepsilon$-caprolactone, PLCL). Other synthetic materials widely used in PNR are polylactic acid (PLA), polylactic-co-glycolic (PLGA), polycaprolactone (PCL), and polyhydroxybutyrate (PHB). In brief, synthetic nerve conduits provide higher degree of controllability, better mechanical properties, and poor bioactivity as compared to their natural equivalents [65]. Moreover, these materials are known for low inflammatory response and effortlessness processing, which means they can be processed in a variety of forms, to enhance nervous tissue growth. However, in spite of the referred positive characteristics of synthetic polymers, a few disadvantages are also reported [85]. The main negative aspects are related to suboptimal biodegradation and possible toxic biodegradation byproducts. These drawbacks block their extended use in the clinics [86]. Fig. 4 shows some promising results considering synthetic biomaterials applied to PNR. From Table 4, it is also possible to find the most recent and relevant reports considering the use of synthetic biomaterials in PNR [87-99].

\section{PLA}

PLA has been used as a nerve conduit material in a few studies. Matsumine et al. [87] developed a biodegradable nerve conduit with PLA non-woven fabric and evaluated its nerve regeneration promoting effect. The conduit made of randomly connected PLA fibers demonstrated a comparable ability as the autograft to induce PNR in the buccal branch of a 7 $\mathrm{mm}$ facial nerve defect. Another author developed a biodegradable multi-layer microbraided PLA fiber-reinforced conduit with outstanding mechanical properties, which revealed to be a promising tool for neuro-regeneration [88]. 


\section{PLLA}

PLLA is the crystalline form of PLA. In a study by Zeng et al. [89], several topographies were achieved in the PLLA conduit using low-pressure injection molding and thermal-induced phase separation, including a nano-fibrous microstructure, microspherical pores and nanofibrous pore walls and a ladder-like microstructure. Of all the topographies experimented, the nano-fibrous microstructure allowed the differentiation of neural stem cells (NSCs) into neurons. Also paying a lot of attention to the inner structure of the NGC, others have developed a conduit that consists of a porous poly(D,L-lactic acid) (PDLLA) tubular support structure with a micropatterned inner lumen pre-seeded with Schwann cells [90]. Such device delivered physical, chemical and biological guidance cues.

\section{PGA}

The use of PGA is not very common in PNR field. However, of the clinically available NGCs, PGA has the most rapid degradation rate and it is FDA-approved (Neurotube $\left.{ }^{\circledR}\right)$. When testing Neurotube ${ }^{\circledR}$ for facial nerve repair, it was found to be an effective substitute to autologous nerve grafts. However, the authors reported a few limitations to this NGC, which consist in the fact that it can only be used with gaps of less than $30 \mathrm{~mm}$, it is quite costly and intolerance cases have been reported [92]. When compared to other FDA-approved conduits, Neurotube ${ }^{\circledR}$ achieved the poorest result in terms of nerve regeneration [91].

\section{PLGA}

PLGA is one of the most attractive synthetic polymers and broadly used in PNR. This FDA-approved material gives rise to very low inflammatory responses, and its degradation can be easily controlled by altering the ratio of its monomer components. Additionally, PLGA scaffolds have the unique ability of adhering to Schwann cells and directing their growth [100]. A recent study focused on producing a laminin-coated and yarn-encapsulated PLGA NGC [93]. The PLGA fiber yarns were fabricated through a double-nozzle electrospinning system and then the PLGA fibrous outer layer was collected using a general electrospinning method. The conduit demonstrated adequate mechanical properties as well as promising potential in promoting Schwann cells proliferation and migration. In another study also focused on different topographies [101], it was developed a hybrid-structured nerve conduit which consists of a PLGA microfibrous bundle wrapped in a micro/nanostructured PLGA membrane. This device demonstrated high capability for guiding nerve cells and promoting cell migration. Many other studies using PLGA 
were developed, inclusively with conduits capable of releasing NTFs or other neuroprotective molecules such as salidriside and Nectin-like molecule 1 (NECL1) [94, 102, 103].

\section{PCL}

PCL is one of the most used polymers in TE [104]. It has been broadly applied in bone [105], cartilage [106], cancer defects [107], and drug delivery applications [108]. It is a biodegradable semi crystalline linear polyester produced by ring-opening polymerisation of $e$ caprolactone with a low melting point of around $60{ }^{\circ} \mathrm{C}$. For the mentioned biodegradable polyesters mentioned so far, in vivo degradation rate is in the order PCL < PLA < PGA. Due to PCL's very low in vivo degradation rate and high drug permeability, it has been found to be useful in long-term implantable delivery devices [109]. Bearing in mind that polymeric bioabsorbable conduits can be used as drug delivery systems, Salmoria et al. [110] produced PCL conduits by melt extrusion technique, which were loaded with ibuprofen. PCL is also a very attractive polymer for the rapidly emerging and recently popular 3D printing technology. In a study recently published by Lee et al. [95], combination of stereolithography and electrospinning techniques allowed to fabricate a novel 3D biomimetic PCL neural scaffold with tunable porous structure and embedded aligned fibers. The results indicated that PCL fibers greatly increased the average neurite length and directed neurite extension of primary cortical neurons along the fiber. Quite often, polyesters are blended with other components to make composite NGCs which allows to improve their mechanical properties and control the general features of the NGCs in more detail [96, 111-114].

\section{$\mathbf{P U}$}

Created by a water-born process, PU has recently been applied as the base material for the construction of a novel NGC [97]. The NGC was built through the freeze-drying technique and presented an asymmetric microporous structure that allowed bridging a 10-mm gap in rat sciatic nerve. The results, in terms of nerve regeneration, were remarkable. Inclusively, based on functional recovery and histology findings, the efficacy of PU NGC was superior to that of commercial conduit Neurotube ${ }^{\circledR}$, to which it was compared. Recently, an antioxidant-PU conduit was developed using the electrospinning technique by Singh et al. [98] and further filled with an aligned chitosan-gelatin cryogel filler. The in vitro cellular tests with dorsal root ganglia (DRGs) cultures showed the aligned growth and cellular migration along the pores, indicating that both the outer part of the conduit as well as the luminal filling are potentially appropriate for PNR. 


\section{PVA}

PVA is another synthetic polymer used in the construction of NGCs. It is water soluble but non-degradable, being considered non-resorbable. There is currently FDA-approved NGCs made of PVA hydrogels, named SaluBridge ${ }^{\mathrm{TM}}$ and SaluTunnel ${ }^{\mathrm{TM}}$. However, such devices have not been validated with accessible pre-clinical or clinical studies. It can also be stated that the utilization of nonabsorbable conduits has declined with the crescent use of absorbable synthetic grafts [115]. To improve that, Stocco et al. [99] recently manufactured a conduit made of a patented and novel biodegradable hydrogel, oxidized PVA (OxPVA). An in vitro and in vivo battery of tests revealed that OxPVA scaffolds performed very similarly to the autograft group. 
A)

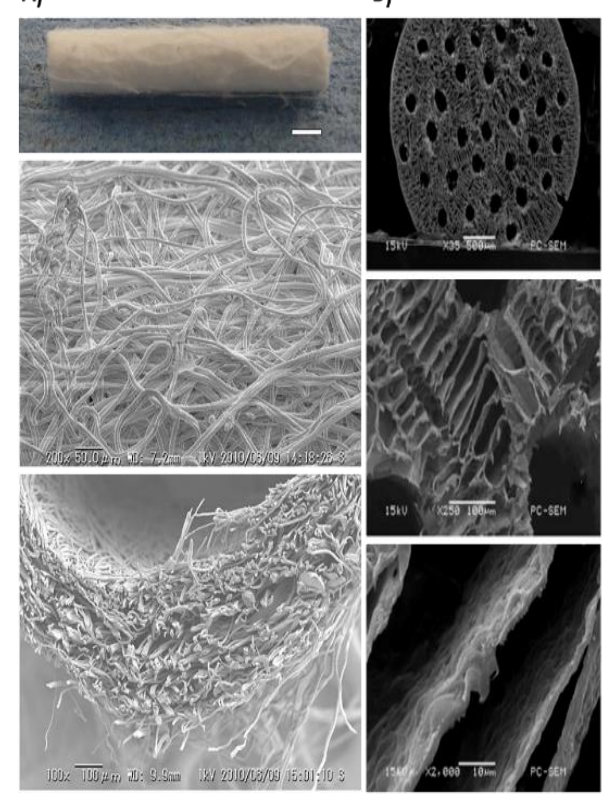

B)

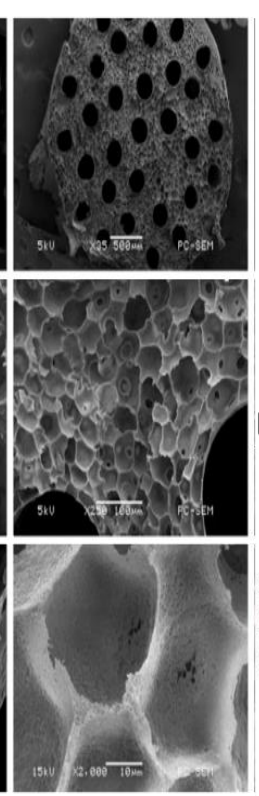

c)

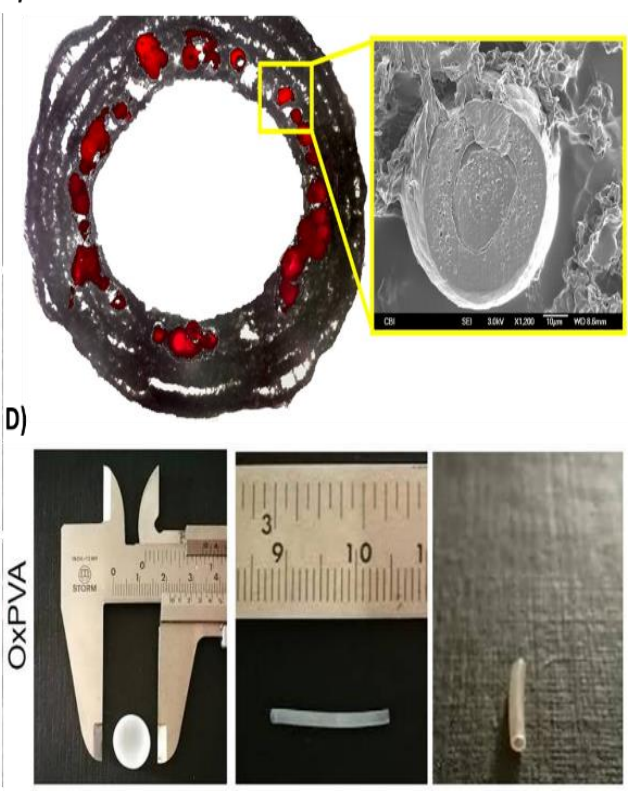

Fig. 4 - Promising results obtained with synthetic polymers applied to PNR. A) A non-woven polylactic acid (PLA) tube. Scale bar: $1 \mathrm{~mm}$; B) SEM images of the PLLA multi-channel conduits cross-section using different magnification. Scale bar: 500, 100 and $10 \mu \mathrm{m}$, from top to bottom; C) Scanning electron micrograph of doublewalled microsphere following incorporation into PCL nerve guides; and D) Gross appearance of disk-shaped and tubular scaffolds made of OxPVA. A), B), C), and D) were reprinted with from [87],[89], [96] and [99], respectively.

\subsubsection{Natural-origin Biomaterials}

Natural-origin biopolymers used for the fabrication of NGCs typically have regenerative bioactivity along with appropriate mechanical properties. Natural biomaterials allow for improved communications between cellular components and the scaffold is also an advantage since cells must be stimulated to proliferate, benefiting tissue regeneration [116]. However, some restrictions are associated to natural-origin biomaterials, such as the batch to batch disparities [117]. In the section below, interesting and recent reports using natural-origin biomaterials for PNR applications, from proteins (e.g., silk fibroin and keratin) to polysaccharides (e.g., chitosan and alginate) will be reviewed. Fig. 5 shows some promising results obtained with natural-origin biomaterials, in particular using silk fibroin, chitosan and alginate polymers. The significant works considering the use of natural-origin biomaterials in PNR are summarized in Table 5 [118-129]. 
Table 4 - Relevant and recent published works focused on the fabrication of NGC with synthetic biomaterials.

\begin{tabular}{|c|c|c|c|c|}
\hline $\begin{array}{l}\text { Conduit } \\
\text { material }\end{array}$ & Fabrication method & $\begin{array}{c}\begin{array}{c}\text { Location, defect size, } \\
\text { model }\end{array} \\
\end{array}$ & Outcomes & $\begin{array}{c}\text { Year, } \\
\text { reference }\end{array}$ \\
\hline \multirow{2}{*}{ PLA } & Non-woven material, melt blown process & Facial nerve, $7 \mathrm{~mm}$ gap, rat & $\begin{array}{c}\text { Comparable ability to induce PNR as autologous } \\
\text { nerve graft. }\end{array}$ & $2014,[87]$ \\
\hline & Multi-layer, micro-braided, fiber-reinforced conduit & $\begin{array}{c}\text { Sciatic nerve, } 10 \mathrm{~mm} \text { gap, } \\
\text { rat }\end{array}$ & Successful regeneration with cables bridging the gap. & $2009,[88]$ \\
\hline \multirow[b]{2}{*}{ PLLA } & $\begin{array}{l}\text { Low-pressure injection molding and thermal-induced } \\
\text { phase separation technique, } 33 \text { inner channel NGC }\end{array}$ & In vitro assays with NSCs & $81.1 \%$ of NCSs differentiated into neurons. & 2014, [89] \\
\hline & $\begin{array}{l}\text { Porous PDLLA conduit achieved by dipping method, } \\
\text { with micropatterned inner lumen by ion etching. Pre- } \\
\text { seeded with Schwann cells }\end{array}$ & $\begin{array}{c}\text { Sciatic nerve, } 10 \mathrm{~mm} \text { gap, } \\
\text { rat }\end{array}$ & $\begin{array}{l}\text { Presence of Schwann cells did not affect results, } \\
\text { speed of functional recovery was enhanced. }\end{array}$ & $2004,[90]$ \\
\hline \multirow{2}{*}{ PGA } & Neurotube $\AA$ is fabricated to form a knitted or woven & $\begin{array}{l}\text { Segmental nerve defect, } 10 \\
\text { mm gap, rat }\end{array}$ & $\begin{array}{c}\text { Exhibited the poorest results for functional motor } \\
\text { recovery in the rat model in comparison to other } \\
\text { FDA-approved conduits. }\end{array}$ & $2009,[91]$ \\
\hline & tubular device & $\begin{array}{l}\text { Facial nerve, } 10-30 \mathrm{~mm} \text { gap, } \\
\text { humans }\end{array}$ & $\begin{array}{l}\text { Valid solution for this kind of defect in emergency. } \\
\text { Associated to some limitation such as high cost and } \\
\text { possible intolerance. }\end{array}$ & $2005,[92]$ \\
\hline \multirow[b]{2}{*}{ PLGA } & $\begin{array}{l}\text { PLGA fibrous outer layer produced by electrospinning and } \\
\text { containing laminin coated yarns obtained by double-nozzle } \\
\text { electrospinning }\end{array}$ & $\begin{array}{l}\text { In vitro assays with } \\
\text { Schwann cells }\end{array}$ & $\begin{array}{l}\text { Significant higher proliferation and elongation of } \\
\text { Schwann cells along the inner yarns. }\end{array}$ & 2017, [93] \\
\hline & $\begin{array}{l}\text { Two concentric biodegradable PLGA tubes enclosing a } \\
\text { NGF reservoir. Solvent casting method }\end{array}$ & $\begin{array}{c}\text { Sciatic nerve, } 15 \mathrm{~mm} \text { gap, } \\
\text { rat }\end{array}$ & $\begin{array}{c}\text { Optimal release levels of NGF; Improved muscle } \\
\text { weight, myelinated nerve growth, and higher target } \\
\text { connection. }\end{array}$ & $2017,[94]$ \\
\hline \multirow[b]{2}{*}{ PCL } & $\begin{array}{l}\text { 3D printed conduit embedded with electrospun aligned } \\
\text { nanofibers }\end{array}$ & $\begin{array}{l}\text { In vitro assays with NSCs } \\
\text { and primary cortical neurons }\end{array}$ & $\begin{array}{c}\text { Increased average neurite length and directed neurite } \\
\text { extension along the fiber. }\end{array}$ & $2017,[95]$ \\
\hline & $\begin{array}{c}\text { PCL conduits were fabricated by dipping and } \\
\text { incorporate double-walled PLGA/PLA microspheres } \\
\text { encapsulating GDNF }\end{array}$ & $\begin{array}{c}\text { Sciatic nerve, } 15 \mathrm{~mm} \text { gap, } \\
\text { rat }\end{array}$ & $\begin{array}{l}\text { GDNF increased tissue formation within the nerve } \\
\text { guide lumen and promoted the migration and } \\
\text { proliferation of Schwann cells. }\end{array}$ & $2010,[96]$ \\
\hline
\end{tabular}


Mold casting followed by freeze-drying, producing a porous scaffold

PU

Electrospun Antioxidant-PU conduit filled with freezedried aligned chitosan-gelatin cryogel

SaluBridge ${ }^{\mathrm{TM}}$, implantable wrap
Sciatic nerve, $10 \mathrm{~mm}$ gap,

rat

In vitro study with neuro $2 \mathrm{a}$, $\mathrm{C} 2 \mathrm{C} 12$ and DRGs.

N/A
Significantly greater efficacy of the PU conduit when compared to the commercial Neuratube ${ }^{\circledR}$.

2017, [97]

DRGs demonstrated aligned growth of the neurites along the pores of the cryogel inside the NGCs.

2018, [98]

No manuscripts have been published regarding this NGC.

Axon density in the middle of the conduit significantly higher as compared to autograft. 


\section{Silk fibroin}

Silk fibroin $(\mathrm{SF})$ is a fibrous protein with remarkable mechanical properties produced by silkworms and spiders [130]. Silk polymers consist of repetitive protein sequences and provide structural roles in nature, such as cocoon formation, nest building and web creation [131]. With very low immunological response, capacity to be transformed in diverse shapes and matrices, tunable degradation as well as easily chemically modified, SF has the potential to impact the clinical needs in terms of nerve regeneration [132]. Beyond PNR, SF has been extensively applied in the TERM field with very distinctive applications [133-135].

Carvalho et al. [71] produced tunable enzymatically cross-linked SF NGCs, resourcing to tyrosine groups present in silk structure that are known for allowing the formation of a covalently cross-linked hydrogel. The fact that the process involves an enzymatic crosslinking allows tuning several parameters in the final conduit, i.e. from its mechanical properties to porosity or biological properties.

A)

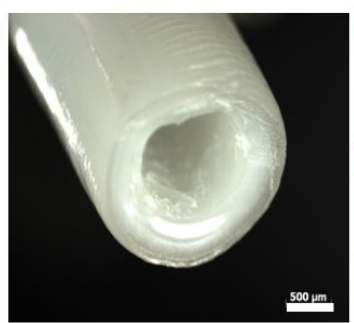

B)

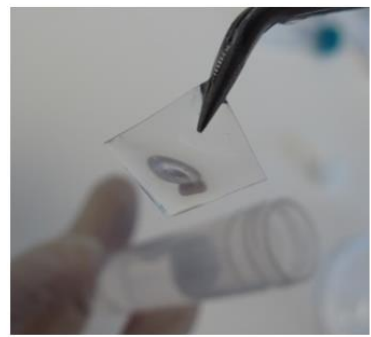

C)

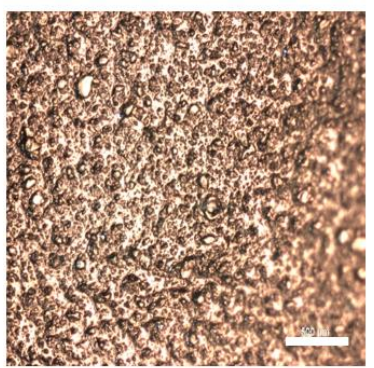

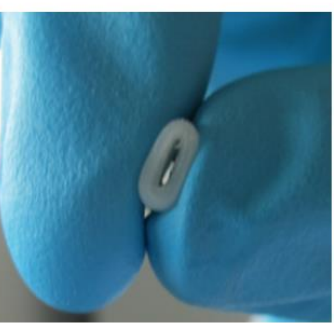
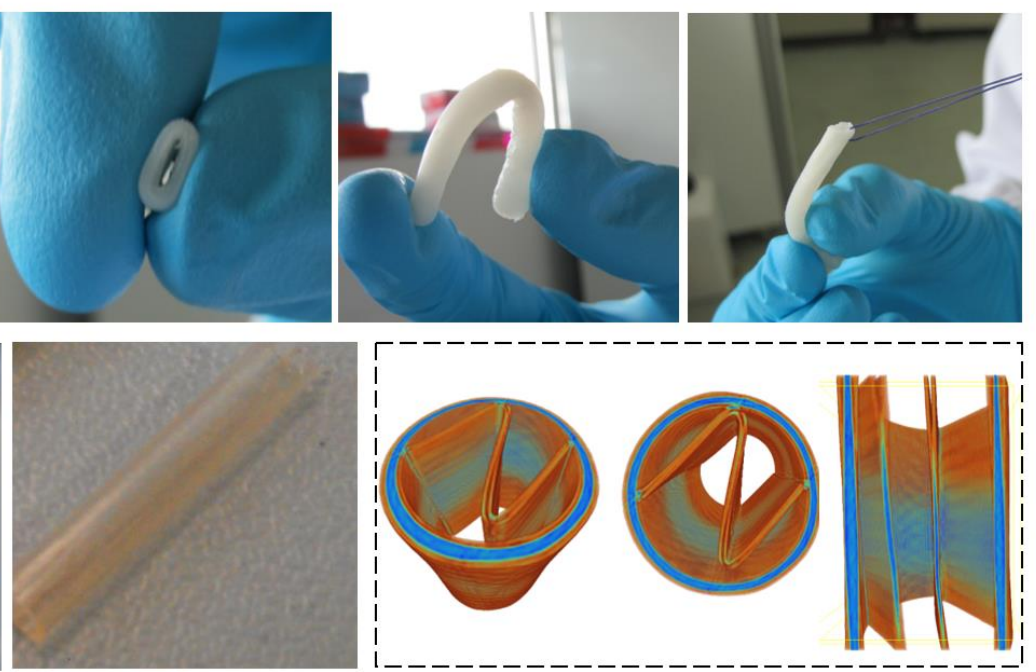

D)
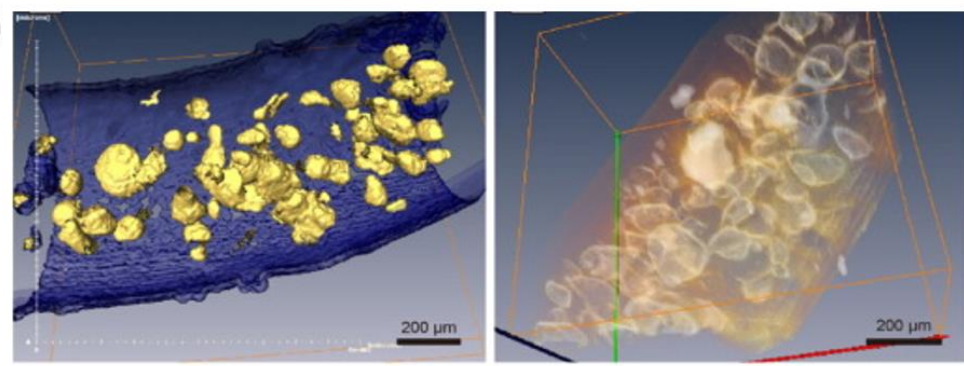

Fig. 5 - Promising results obtained with natural-origin polymers applied to PNR. A) Example of an enzymatically crosslinked SF nerve guidance conduit developed and patented by Carvalho et al. [71] for application in PNR. The developed NGC presents outstanding mechanical properties, with kinking-resistant 
capacity and suturability, as can be seen by the images (in that row); (B) Images of a 5\% of degree of acetylation chitosan membrane, which can be further used as a NGC by rolling-up or in a different strategy, as a luminal filler; C) $5 \%$ degree of acetylation chitosan membrane incorporating human hair keratin, developed at our research institute; and D) Confocal laser microscopy showing macroporous alginate fibers incorporating gelatin particle porogens. Scale bars: $500 \mu \mathrm{m}$.

One of the advantages of SF relies on the ability to be processed in a variety of shapes. Dinis et al. [136] developed a 3D multi-channel SF conduit through electrospinning system encompassing approximately 12 multi-channel guides of different sizes inside the main conduit, mimicking the native structure of the nerve endoneurium, perineurium, and epineurium. In fact, due to the outstanding properties that several silk NGC have demonstrated after decades of research, there is an active clinical trial (NCT03673449) with SilkBridge. Such device is a biocompatible SF-based matrix that aims at attracting the patients' native cells to regenerate the nerve, i.e. without the need to add cellular components previous to the implantation. The SilkBridge is also being used in digital nerve defects.

\section{Keratin}

Keratin protein has been recognized as biomaterial with high potential due to its excellent bioactivity and biocompatibility [137]. Lately, the hair keratin has gained much attention [138, 139], not only because of its properties, but because the follicle itself is a bizarrely proliferative organelle that illustrates an extremely arranged regenerative process. Also, the fact that it is potent naturally derived biomaterial, is human-derived and possesses cellular interaction sites making it an attractive protein in TE applications [140].

So far, little has been done concerning the application of hair keratin to PNR. All in vivo work done with keratin in the scope of PNR has been developed under the supervision of the scientist Van Dyke at the Wake Forest University [122-124, 141].

\section{Chitin and Chitosan}

Chitin and chitosan are two of the most popular natural biopolymers in the TE field, as well as in the area of nerve repair [142]. Chitin is a natural biopolymer normally present in the exoskeletons of arthropods and the shells of crustaceans, being the main sources, in fact, the marine crustaceans such as shrimp and crabs. It is a linear homopolymer composed of N-acetyl-D-glucosamine units that form beta-(1-4)-linkages. The most abundant polysaccharide in nature is cellulose, immediately followed by chitin [143]. On the other hand, chitosan is obtained through the partial deacetylation of chitin. 
It is a polysaccharide composed of D-glucosamine and N-acetyl-D-glucosamine units linked through beta-(1-4)-glycosidic bonds. Soluble in acidic aqueous media, chitosan, is finding applications in many areas, such as food, cosmetics and biomedical fields [144].

It has early been proved that chitin and chitosan-based scaffold can allow the attachment, migration, and proliferation of Schwann cells as well as of DRGs, two of main players in the nerve regeneration process [145-148]. Furthermore, chitosan biomaterials encourage the aligned orientation of Schwann cell and growing axons [149151], which is a relevant phenomenon in the process of Wallerian degeneration and consequent regeneration. Additionally, chitosan-based NGCs are easily handled, and transparency facilitates surgical manipulation and suturing of the nerve stumps.

Due to the recognized potential of chitosan, a chitosan-based nerve conduit under the name Reaxon ${ }^{\circledR}$ Nerve Guide manufactured by Medovent GmbH (Mainz, Germany), in accordance with the international standard DIN EN ISO 13485, was launched in the market in 2014. These conduits were thoroughly investigated in a report by HaastertTalini et al. [152], where the referred conduits combined several pre-requisites for a clinical acceptance; and the tube with a degree of acetylation of 5\% was considered as the most supportive for peripheral nerve regeneration to bridge a $10 \mathrm{~mm}$ gap. That conduits were used in a critical sized nerve gap [64] and in type 2 diabetic Goto-Kakizaki rats [153], confirming their good in vivo performance.

\section{Alginate}

Alginate is a broadly used bioresorbable polysaccharide in the food industry, wound management or in the TE field. It is a block co-polymer consisting of beta-dmannuronic acid and alpha-l-guluronic acid, extracted from brown seaweed [154]. It is considered a biocompatible material which has no inhibitory effect on cell proliferation in vitro and induces reduced foreign body reaction when implanted in tissues in vivo [155]. It has been described that calcium ions induce specific associations between alginate chains, consequently forming hydrogels [156]. Using such mechanism, previous studies $[157,158]$ have shown the possibility to use alginates applied to PNR. Namely, a decomposable freeze-dried alginate gel covered by PGA mesh was employed in a $50 \mathrm{~mm}$ gap in a cat sciatic nerve model with positive results [157]. The same authors later examined the interaction between regenerating axons, Schwann cells and the implanted alginate gel [158], showing that alginate gel provides a good environment for axon 
outgrowth and Schwann cell migration. In another study [128], macro-porous alginate fibres encapsulating primary DRGs were produced by wet spinning an alginate solution containing dispersed gelatine particles. Marked neurite outgrowth was evident over 150 $\mu \mathrm{m}$, indicating that pores and channels created within the alginate were providing a favourable environment for neurite development. Other studies have focused on using alginate as NGCs luminal fillers, with promising results [159-161].

\subsubsection{Endogenous Biomaterials/ECM proteins}

Still among the natural-origin biomaterials, ECM endogenous proteins such as collagen, fibrin, laminin, and hyaluronic acid (HA) have been highly investigated, since they naturally exist in the human body. ECM is a highly organized 3D structure that occupies the intercellular space, providing a physical support to tissue. It fundamentally acts as a natural scaffold by delivering a matrix, where cells can arrange within the connective tissue. Besides delivering the physical support, ECM also provides the chemical setting for adequate cellular behavior in terms of survival, differentiation and overall fate. Furthermore, Schwann cells express specific integrins, such as $\alpha_{1} \beta_{1}, \alpha_{2} \beta_{1}, \alpha_{6} \beta_{1}, \alpha_{6} \beta_{4}, \alpha_{5} \beta_{1}, \alpha V \beta_{3}$, that connect to ECM and encourage myelination through their interaction with the basal lamina [162]. The important interaction between ECM molecules and the nervous system can also be inferred from the fact that laminin, fibronectin and collagen are effectively used as coatings of tissue culture plastics to enhance Schwann cell and DRGs responses, such as adhesion and migration [163].

A few recent publications related to the use of endogenous biomaterials applied to PNR can be found in Table 6 [164-174]. Furthermore, Fig. 6 summarizes the promising results making use of endogenous biomaterials applied to PNR. 
Table 5 - Relevant and recent published works focused on the fabrication of NGC with natural biomaterials.

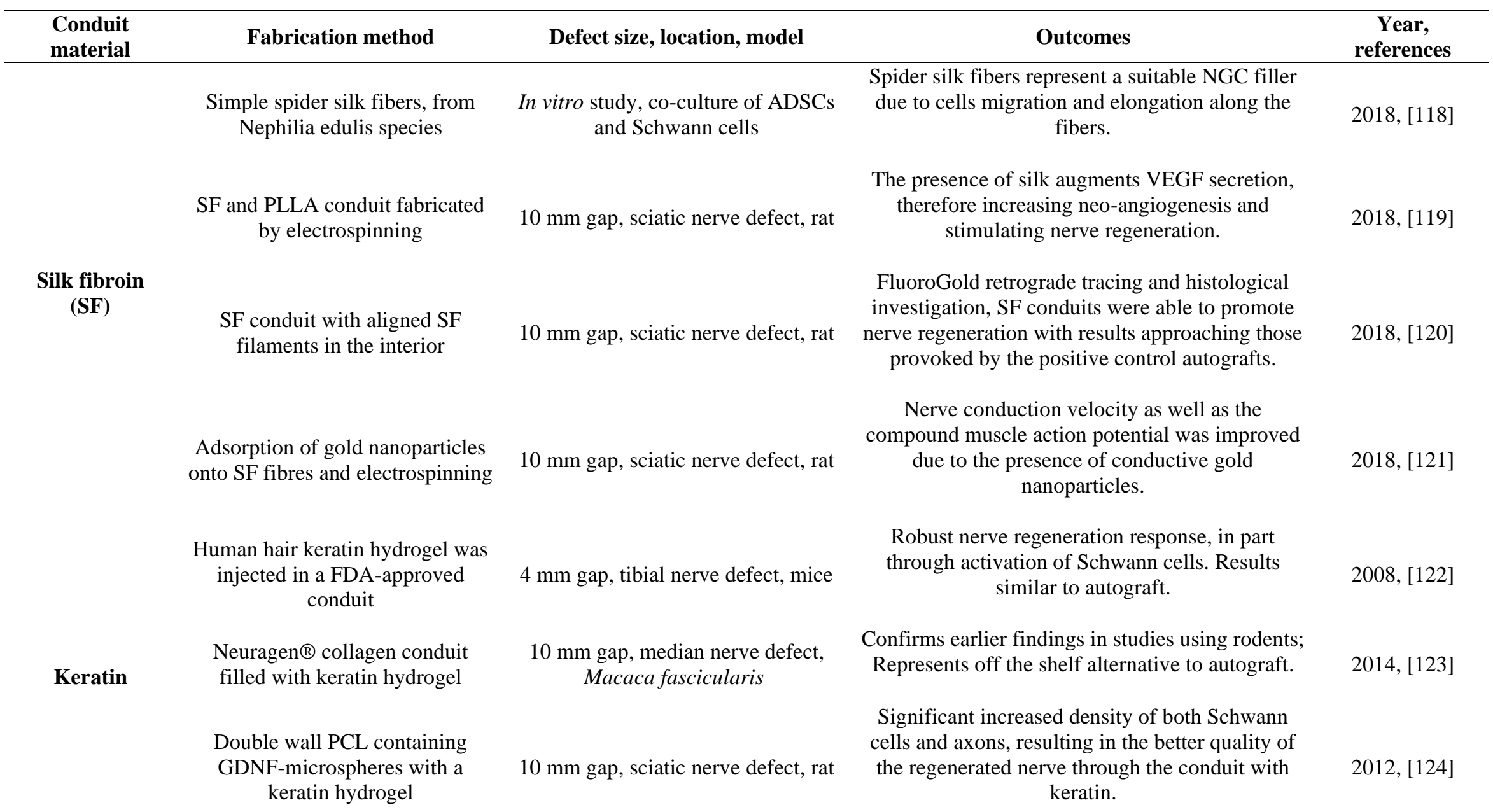


Chitosan nerve guides from Reaxon ${ }^{\circledR}$ with a longitudinal chitosan film as a filler

Chitosan film enhanced with MSCs

\section{Chitosan}

Chitosan membranes with different degrees of acetylation

Combination of MSCs with a chitosan a film

Macroporous alginate fibers produced with a syringe pump

\section{Alginate}

3D bioprinting of alginate scaffolds conjugated with single or dual RGD and YIGSR motifs
$15 \mathrm{~mm}$ gap, sciatic nerve defect, diabetic rat

10 mm gap, sciatic nerve defect, rat

Schwann cell and fibroblast in vitro assays

$10 \mathrm{~mm}$ gap, sciatic nerve defect, rat

In vitro assays with DRGs

In vitro assays with Schwann cells and DRGs
Supported robust axonal regeneration and

functional recovery in healthy animals but also demonstrated to be beneficial for the regeneration

process in diabetic rats with relevant blood glucose levels.

Chitosan film enhanced with MSCs improved functional, electrophysiological and histomorphometry recovery of transected sciatic nerves.

$\%$ of acetylation were found to favor Schwann cells invasion and proliferation, presenting at the same time low fibroblast adhesion.

MSCs were useful for the injury because of the release of several neurotrophic factors as well as the synergistic effect of chitosan accelerating wound healing by promoting an antiinflammatory effect.

Encapsulation of primary DRGs in macro-porous alginate fibers resulted in marked neurite outgrowth over $150 \mu \mathrm{m}$.

Printability, mechanical stability, and neurite outgrowth were assessed with promising results to be used as luminal filler. 


\section{Collagen}

Collagen is, within the ECM, probably the major organizational and structural protein of hard and soft tissues. It provides strength, mechanical stability, structural integrity and plays a crucial biological role in a variety of tissues and organs including, bone, cartilage, tendon, skin, and cornea[175]. To achieve that, collagen is extremely dynamic, undergoing constant modifications to deliver proper physiologic functions [131]. Although collagen offers structure to our bodies, protecting and supporting the soft tissues, collagen is a relatively simple protein, containing a triple-helical structure and the presence of 4-hydroxyproline. Up to this date, 28 collagen types have been acknowledged. The types I, II, III, and V constitutes the essential part of collagen in bone, cartilage, tendon, skin, and muscle. Collagen can be extracted and purified from a variety of sources, typically from bovine and porcine sources. However, in recent years new sources are being exploited, such as marine-origin residues [176]. The fact that collagen is considered low immunogenic and has good permeability, biocompatibility, and biodegradability make it a great component for TE scaffolding strategies [177].

Collagen use in PNR approaches is also extensively accepted, as the protein often exhibits cell-binding domains for aiding neuronal and glial cells attachment and migration. In fact, three collagen conduits are commercially available on the market: The FDA-approved NeuraGen ${ }^{\circledR}$ and NeuroFlex ${ }^{\circledR}$, which are both made of type I collagen and RevolNerve ${ }^{\circledR}$, which is made of type I and type III collagens from porcine skin. In a pioneering strategy, Neuromaix ${ }^{\circledR}$ containing collagen-based micro-structured 3D longitudinal guidance channels is capable of providing mechanical support to sprouting DRGs axons and can offer a shielding niche for nerve cells [178].

\section{Fibrin}

In the human body, fibrin is an integral part of the clotting cascade. When the coagulation cascade is triggered after an injury, thrombin activates soluble plasma protein fibrinogen, resulting in the formation of an insoluble fibrin milieu. Fibrin is a protein involved in the formation of the blood clot [179]. It has found application as a sealant glue in neurosurgery for decades, without any reported complications [180]. Furthermore, fibrin plays a critical part in PNR, where longitudinally oriented fibrin cables are formed spontaneously shortly after injury, as a part of the nerve regeneration process, with the intent to direct migration and proliferation of Schwann cells. In fact, the use of fibrin to 
repair ilioinguinal nerve has shown to have some neuroprotective effect in the injured nerve, where less fibrosis and collagen deposition were found [181].

\section{Fibronectin}

Fibronectin, one of the most complex and intrigguing proteins, is an abundant soluble constituent of plasma and other body fluids and part of the insoluble ECM. It also mediates a wide variety of cellular interactions with the ECM and plays important roles in cell adhesion, migration, growth and differentiation [182]. After extensive characterization, it was found that fibronectin expresses the RGD motif, related to cell adhesion. However, fibronectin has an extensive variety of practical functions other than associate with cell surfaces through integrins. It binds to several biologically important molecules that include heparin, collagen and fibrin. The potential of including fibronectin for PNR was firstly realized when Whitworth et al. [183] reported a new nerve conduit material consisting of orientated strands of the cell adhesive fibronectin. In a $10 \mathrm{~mm}$ nerve defect in rat, the developed NGC produced the highest rate and amount of axonal regeneration, comparable to the one obtained for autografts. Furthermore, increased expression of fibronectin can be found in damaged peripheral nerve during Wallerian degeneration [184].

\section{Laminin}

Laminin is a glycoprotein naturally occurring in nerves. It is a component of ECM that plays a decisive part in cell-recognition, and therefore influences cell migration, differentiation and axonal growth [185]. Laminin can also be perceived as a fundamental guiding cue, since the growth cone of regenerating axons is attracted to laminin [186]. To make PHBV aligned nanofibers more attractive to neuronal components[187], laminin was adsorbed via electrostatic interactions. Containing both topographic and chemical cues suited for Schwann cell alignment and elongation, the developed NGC was implanted in a critical sized nerve defect in rat, with $12 \mathrm{~mm}$ gap and proved to be suitable for such an application. 
Table 6 - Relevant and recent published works focused on the fabrication of NGC with endogenous biomaterials.

\begin{tabular}{|c|c|c|c|c|}
\hline Conduit material & Fabrication method & Defect size, location, model & Outcomes & $\begin{array}{c}\text { Year, } \\
\text { references }\end{array}$ \\
\hline \multirow[b]{2}{*}{ Collagen } & $\begin{array}{l}\text { Oriented collagen tubes with } \\
\text { adsorbed bFGF }\end{array}$ & $15 \mathrm{~mm}$, sciatic nerve defect, rat & $\begin{array}{l}\text { The presence of bFGF revealed to be beneficial } \\
\text { in terms of functional recovery. }\end{array}$ & 2017, [164] \\
\hline & $\begin{array}{c}\text { Blend of collagen and chitosan } \\
\text { as luminal filler in a PCL } \\
\text { conduit }\end{array}$ & $15 \mathrm{~mm}$, sciatic nerve defect, rat & $\begin{array}{l}\text { Axonal regeneration and Schwann cell } \\
\text { migration, inclusively inducing comparable } \\
\text { functional recovery to that of the autograft } \\
\text { control group. }\end{array}$ & $2018,[165]$ \\
\hline \multirow{3}{*}{ Fibrin } & $\begin{array}{l}\text { Micro-suturing with fibrin glue } \\
\text { coaptation }\end{array}$ & $10 \mathrm{~mm}$, sciatic nerve defect, rat & $\begin{array}{l}\text { Reduced the operating time and increase the } \\
\text { regeneration distance as well as increasing the } \\
\text { arborizing axons. }\end{array}$ & 2013, [166] \\
\hline & $\begin{array}{l}\text { Epineural repair with fibrin- } \\
\text { glue embedded ADSCs }\end{array}$ & $10 \mathrm{~mm}$, sciatic nerve defect, rat & $\begin{array}{l}\text { Embedding cellular components in the fibrin } \\
\text { glue enhanced regeneration, as immunolabeled } \\
\text { cells could be found at the neuronal repair site } \\
\text { and near intraneuronal vessels indicating an } \\
\text { active participation of ADSCs in the process of } \\
\text { nerve angiogenesis. }\end{array}$ & 2016, [167] \\
\hline & $\begin{array}{l}\text { 3D hierarchically aligned fibrin } \\
\text { nanofiber hydrogel through } \\
\text { electrospinning and molecular } \\
\text { self-assembly and placed it } \\
\text { inside chitosan conduits }\end{array}$ & $10 \mathrm{~mm}$, sciatic nerve defect, rat & $\begin{array}{l}\text { In vitro, directional cell adhesion and migration } \\
\text { of Schwann cells and DRGs was detected. In } \\
\text { vivo, results showed that the developed NGC } \\
\text { performed similarly to the autologous nerve } \\
\text { graft. }\end{array}$ & 2017, [168] \\
\hline \multirow[b]{2}{*}{ Fibronectin } & $\begin{array}{l}\text { Chitosan conduit enriched with } \\
\text { fibronectin }\end{array}$ & $15 \mathrm{~mm}$, sciatic nerve defect, rat & $\begin{array}{l}\text { Fibronectin-enriched scaffolds increased } \\
\text { muscle reinnervation and the number of } \\
\text { myelinated fiber. }\end{array}$ & $2017,[170]$ \\
\hline & $\begin{array}{l}\text { Schwann cells embedded in a } \\
\text { matrix of alginate/ fibronectin }\end{array}$ & $10 \mathrm{~mm}$, sciatic nerve defect, rat & $\begin{array}{l}\text { Synergistic effect when both Schwann cells and } \\
\text { fibronectin were combined with alginate. }\end{array}$ & 2003, [169] \\
\hline
\end{tabular}


Laminin

namofibers were produced by electrospinning

Direct injection of laminin in a peroneal nerve crush

Electrospinning of a blending of $\mathrm{HA}$ in PCL

Single-channel tubular conduits based on hyaluronic acid (HA)

with and without poly-l-lactide acid fibers in their lumen were fabricated
In vitro studies with neonatal Schwann cells

Nerve crush defect, rat

In vitro cells tests with $\mathrm{SH}$ SY5Y human neuroblastoma cell line

\section{Hyaluronic acid (HA)}

Schwann cells expressed bi- and tri-polar elongations due to the presence of laminin.

2014, [171]

Increased axon presence, larger axon diameter, accelerated axon growth and maturity and advanced motor function recovery.

PCL/HA 95:5 exhibit the most balanced properties to meet the required specifications for neural cells.

impeded the leakage of the cells seeded in their interior and made them impervious to cell

invasion from the exterior, while allowing

transport of nutrients and other molecules needed for cell endurance. The NGC interior tubular surface was completely covered with Schwann cells. 
A)
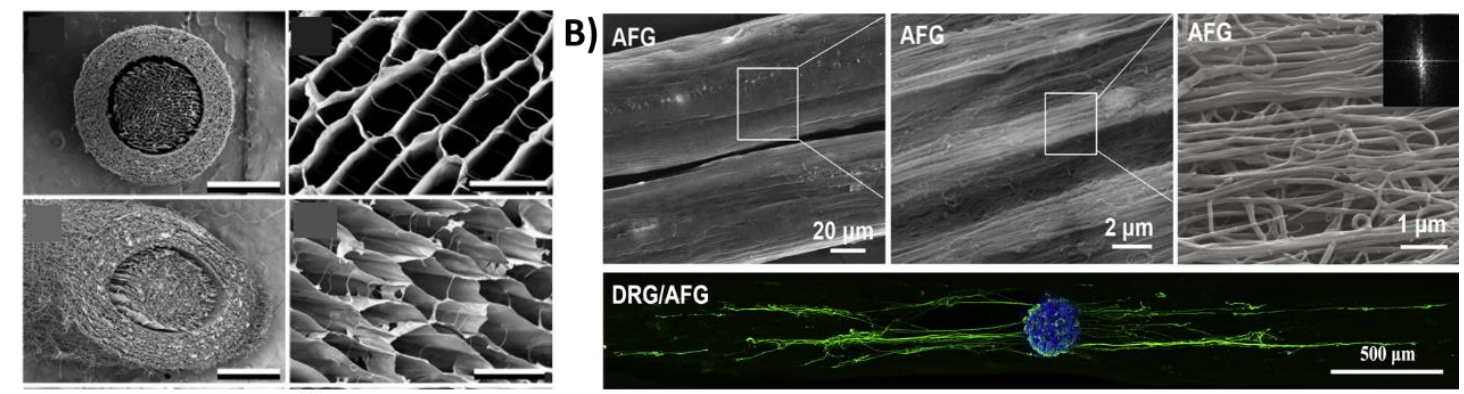

DRGIAFG

C)
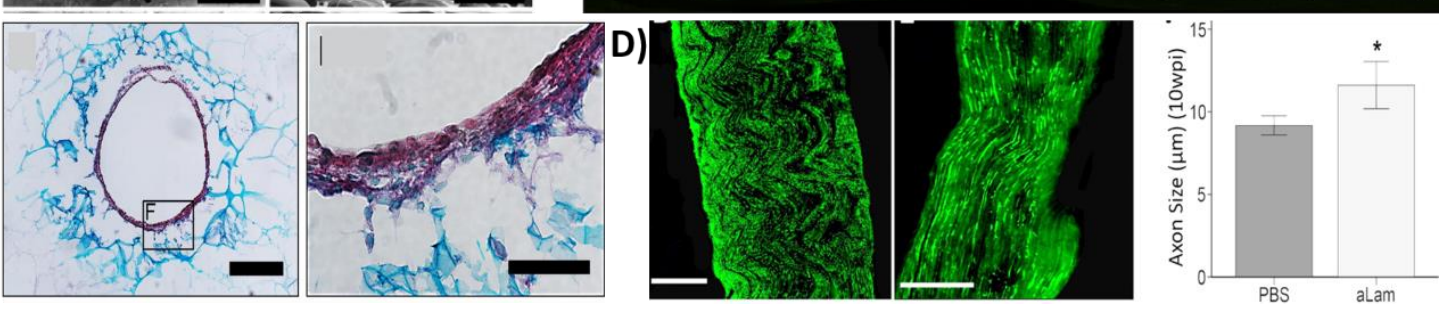

Fig. 6 - Promising results obtained with natural-origin polymers applied to PNR. A) SEM micrographs of transverse section of the oriented collagen-chitosan filler /PCL sheath scaffold and magnification of the interior of the conduit; B) SEM micrograph of the aligned fibrin hydrogel nanofiber and its magnification. Below, a DRGs where the neurites align along the aligned fibers; C) Transversal cryosections of hyaluronic acid conduits cultured for 10 days with Schwann cells in their lumen, after staining with Harris' hematoxylin, Alcian blue, and picrosirius red; and D) Longitudinal section of injured nerve treated with PBS (at left) or Laminin (at right), stained with antibodies recognizing NF-h ( $\alpha$-RT97, green). The bar graph illustrates significantly increased axon diameter $(\mu \mathrm{m})$ with laminin treatment. A), B), C) and D) were reprinted with the permission from [165], [168], [174] and [172] respectively.

Laminin was also added to collagen gels in a gradient of concentrations with interesting effects [188]. For collagen gels without laminin, a typical bimodal response of neurite outgrowth was observed, with increased growth at lower concentrations of collagen gel. However, in the presence of higher laminin concentrations, the growth became independent of the gel stiffness.

\section{Hyaluronic acid (HA)}

HA is a linear, anionic, non-sulphated glycosaminoglycan that composes the ECM of all living tissues. Being a very versatile polymer, it finds applications in diverse areas. Furthermore, different molecular weights have an impact on the biological performances, being a highly tunable and adaptable polysaccharide [189].

Its use is widely spread in TE applications due to its biocompatibility, biodegradability and chemical modification easiness. HA is also a very versatile biomaterial, which can be prepared in the form of hydrogels, sponges, cryogels, and injectable hydrogels [190]. Additionally, HA degradation products seem to exert a positive effect in diverse TE areas as they encourage wound healing, tissue restoration, and vascularization [191]. The injection of HA in a nerve defect has proved to be beneficial for nerve regeneration, since HA groups showed an increase in myelinated 
axon counts, as well as an increase in retrograde flow, necessary for the regenerative process [192]. Furthermore, the advantage of including HA also resides in the fact that it can reduce scar formation after nerve injury [193].

\subsubsection{The possibility of patient-specific nerve repair and NGCs}

Personalized TE and regenerative strategies propose a possible solution for contemporary untreatable injuries or illnesses. The use of TE triad offers the possibility of interminable combinations of cells, scaffolds and growth factors, suggesting endless possibilities to customize diagnostic tools, biomedical devices, as well as the final treatments [194]. Huge efforts are being carried in laboratories throughout the world to personalize the clinical care, catalyzing major advances in the techniques that allow the treatment of serious injuries and chronic diseases [195]. The customization and individualization of medical care carries huge advantages for the patients and the health care systems as well. Targeting the treatments to a specific damage of a patient is critical due to innate discrepancies in patient anatomies, injury shapes and gravity, as well as individual genetic and proteomic features [196]. The benefit is clear for the patient, i.e. a tailor-made treatment according to its own organism features. For the hospitals and healthcare systems, the fact that a treatment is $100 \%$ suited for that specific patient and will not fail, will save time and budget.

Peripheral nerves are tissues with different geometries and shapes, which vary anatomically according to the location within the body. But more importantly, the same nerve may vary from person to person with age, according to their medical condition or type of injury [197]. Furthermore, the process of nerve regeneration and repair itself is a complex biological phenomenon, with vast singularities, that requires an equilibrium at a molecular, cellular and tissue level [198]. Overall, many advantages are envisioned when using 3D printing for nerve repair and regeneration: (i) fabrication of personalized NGC, (2) concomitant assembly of luminal fillers inside NGCs, (3) 3D bioprinting of cells within a bioink or into the NGCs, and (4) establishment of growth factor gradients or pathways [199].

Only recently the hypothesis of patient-specific strategies in nerve regeneration has risen with the development of the 3D-printing technology [200]. This was further permitted by the combination of 3D imaging machineries and 3D printing methods. 
Johnson et al. [200] successfully established the combination of 3D imaging and 3D printing for the design and fabrication of anatomically biomimetic truly patient-specific nerve regeneration strategy. It allowed the fabrication of NGCs with complex anatomical structures and inner biofunctionalization with neurotrophic factors, to create a sensory and a motor pathway (Fig. 7A).

Hu et al. [201] explored the 3D-printing technology to prepare a bio-conduit with designer structures for PNR, where the chosen polymer, cryoGelMA gel, was cellularized with ADSCs. When implanted in a $10 \mathrm{~mm}$ rat sciatic nerve defect, the results were very similar to the autograft in terms of functional recovery. Tao et al. [202] were able to 3D-print an hydrogel conduit with customized size, shape and structure, providing a physical microenvironment for axonal elongation, where the nanoparticles sustained release a drug to facilitate the nerve regeneration. Zohng et al. [203] described the key technology of 3D peripheral nerve fascicle reconstruction. First, a 3D virtual model of internal fascicles was obtained and successfully applied for 3D reconstruction for the median nerve (Fig. 7B).

Exceptional technologies are emerging every day, and 3D printing promises to revolutionize the patient-specific healthcare, namely in PNR.

A)
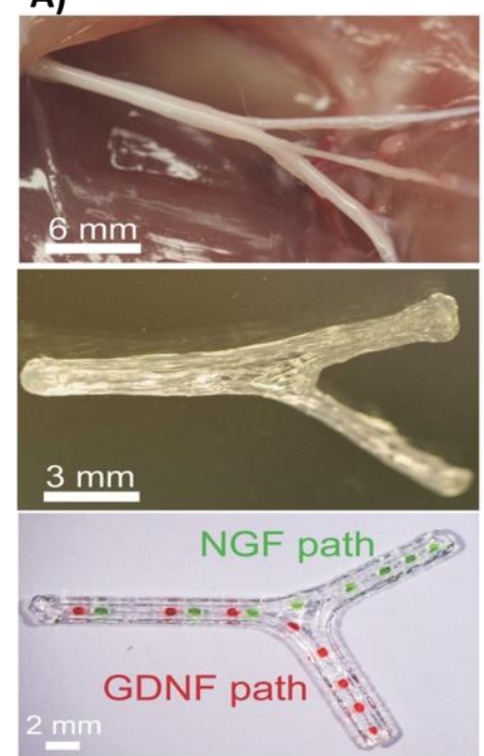

Fig. 7 - Patient-specific and 3D printing technologies will allow improving the treatment given to patients in the future. A) 3D printed complex nerve pathways from 3D scanned bifurcating nerves. Reprinted with permission from [200]. B) Imaging of a 3D model of median nerve, for further precise reconstruction. Reprinted with permission from [203], Copyright (C) 2015, Macmillan Publishers Limited.

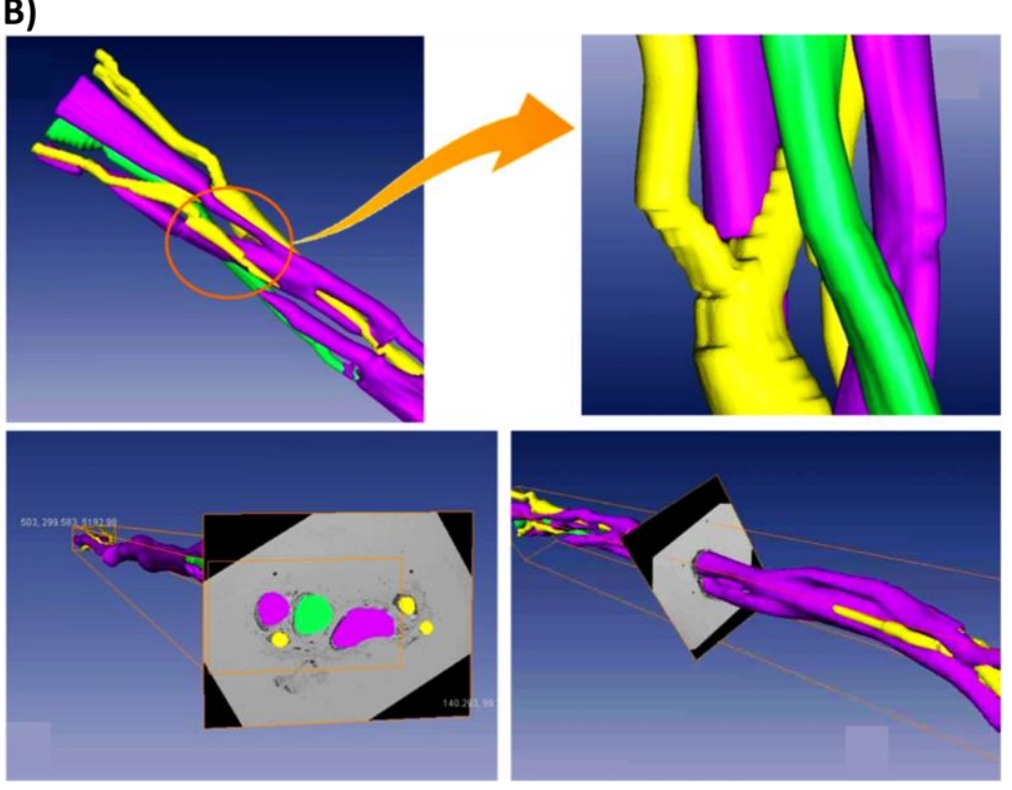

\footnotetext{
.
}




\section{CONCLUSIONS}

The complex anatomy and physiology of the PNS makes nerve's injury very problematic and extremely difficult to repair. The full recovery is challenging because of the loss of native cues, formation of scar tissue, lack of proper vascularization, and inflammation. The diverse treatments used for nerve repair such as coaptation suturing, grafts, and conduits pose several limitations when trying to recuperate full functionality. Therefore, the development of new NGCs requires a clever combination of the following strategies: (i) the development of new polymer or combination of polymers for better integration with neural native tissue, (ii) additional of topographical structures to intensify neurite alignment and growth, and (iii) biological cues such as growth factors or cellular components.

In what regards the biomaterial choice, there are numerous options to capitalize on different properties of each material. Although many exist and can be used, natural materials are known to be better integrated by host tissue when compared to synthetic ones, more promptly instigating the regenerative mechanisms. The biomaterial availability and cost are also essential parameters to consider. Therefore, and in the author's opinion, SF is probably one of the most versatile biomaterials. It can be processed in a variety of ways and maintain outstanding mechanical properties/suturability and is considered non-immunogenic, with cheap and easy access as well as natural distribution. This biomaterial can be used to fabricate the conduit itself, as well as anisotropic filling scaffolds in the lumen, in order to be able to treat larger nerve gaps. In addition, several fabrication methods can be used for this biomaterial, including the crosslinking of the tyrosine groups with an enzymatic mediated system or functionalization with growth factors and other molecules of interest. In this context, conductive materials can also be used to intensify the needed neurological transmission and communication.

A brief mention must also be made to the potential of 3D printing for patientspecific nerve reconstructions. The rising of this technology allows to closely reproduce features of the native peripheral nerve, with the aim of possibly replace autologous nerve grafts. Therefore, the current and future bio-imaging modalities allied with detailed printing will permit the production of patient-specific nerve conduits, revolutionizing the field. As the scientific community makes advances on the fundamental knowledge related 
to the biological mechanisms behind nerve injury and repair, engineers are able to integrate that knowledge in more complex designs, to better mimic natural nerve regeneration and patient specificity in respect to anatomy and biology requirements.

\section{Acknowledgments}

This work was supported by Cristiana Carvalho PhD scholarship (Norte-08-5369-FSE000037). J. M. Oliveira also thanks the FCT for the funds provided under the program Investigador FCT 2015 (IF/01285/2015). The authors are also thankful to the FCT funded project NanoOptoNerv (ref. PTDC/NAN-MAT/29936/2017). The authors would also like to acknowledge the project: "Nano-accelerated nerve regeneration and optogenetic empowering of neuromuscular functionality" (ref.PTDC/NAN-MAT/29936/2017).

\section{REFERENCES}

1. Battiston, B., et al., Chapter 1: Peripheral nerve repair and regeneration research: $a$ historical note. Int Rev Neurobiol, 2009. 87: p. 1-7.

2. Belen, D., A. Aciduman, and U. Er, History of peripheral nerve repair: may the procedure have been practiced in Hippocratic School? Surg Neurol, 2009. 72(2): p. 1903; discussion 193-4.

3. Wu, D. and A.K. Murashov, Molecular mechanisms of peripheral nerve regeneration: emerging roles of microRNAs. Frontiers in physiology, 2013. 4: p. 55-55.

4. Geuna, S., P. Tos, and B. Battiston, Emerging issues in peripheral nerve repair. Neural regeneration research, 2012. 7(29): p. 2267-2272.

5. Zhang, P.-X., et al., Tissue engineering for the repair of peripheral nerve injury. Neural Regeneration Research, 2019. 14(1): p. 51-58.

6. Siemionow, M., M. Bozkurt, and F. Zor, Regeneration and repair of peripheral nerves with different biomaterials: review. Microsurgery, 2010. 30(7): p. 574-88.

7. Pixley, S.K., et al., Evaluation of peripheral nerve regeneration through biomaterial conduits via micro-CT imaging. Laryngoscope investigative otolaryngology, 2016. 1(6): p. $185-190$.

8. Herculano-Houzel, S., Chapter 1 - Brain Evolution, in The Human Nervous System (Third Edition), J.K. Mai and G. Paxinos, Editors. 2012, Academic Press: San Diego. p. 2-13.

9. Balaji, S., et al., Preparation and comparative characterization of keratin-chitosan and keratin-gelatin composite scaffolds for tissue engineering applications. Materials Science and Engineering: C, 2012. 32(4): p. 975-982.

10. Lobko, P.I., et al., Ganglia formation of the peripheral nervous system. Acta Anat (Basel), 1979. 103(4): p. 395-9.

11. Payne, S.L., et al., Chapter 68 - Central Nervous System, in Principles of Regenerative Medicine (Third Edition), A. Atala, et al., Editors. 2019, Academic Press: Boston. p. 1199-1221.

12. Birch, R., et al., The Peripheral Nervous System: Anatomy and Function, in Peripheral Nerve Injuries: A Clinical Guide. 2013, Springer London: London. p. 1-67. 
13. Fricker, M., et al., Neuronal Cell Death. Physiol Rev, 2018. 98(2): p. 813-880.

14. Rotshenker, S., Wallerian degeneration: the innate-immune response to traumatic nerve injury. J Neuroinflammation, 2011. 8: p. 109.

15. Grinsell, D. and C.P. Keating, Peripheral Nerve Reconstruction after Injury: A Review of Clinical and Experimental Therapies. BioMed Research International, 2014. 2014: p. 13.

16. López-Cebral, R., et al., Peripheral Nerve Injury: Current Challenges, Conventional Treatment Approaches, and New Trends in Biomaterials-Based Regenerative Strategies. ACS Biomaterials Science \& Engineering, 2017. 3(12): p. 3098-3122.

17. Gaudin, R., et al., Approaches to Peripheral Nerve Repair: Generations of Biomaterial Conduits Yielding to Replacing Autologous Nerve Grafts in Craniomaxillofacial Surgery. BioMed research international, 2016. 2016: p. 3856262-3856262.

18. Rosso, G., et al., Unravelling crucial biomechanical resilience of myelinated peripheral nerve fibres provided by the Schwann cell basal lamina and PMP22. Scientific Reports, 2014. 4: p. 7286.

19. Zhu, S., et al., A synthetic oxygen carrier-olfactory ensheathing cell composition system for the promotion of sciatic nerve regeneration. Biomaterials, 2014. 35(5): p. 14501461.

20. Shoichet, M.S. and R. Midha, Peripheral nerve regeneration through guidance tubes $A U$ - Belkas, Jason S. Neurological Research, 2004. 26(2): p. 151-160.

21. Jaquet, J.B., et al., Median, ulnar, and combined median-ulnar nerve injuries: functional outcome and return to productivity. J Trauma, 2001. 51(4): p. 687-92.

22. Kawano, H., et al., Role of the lesion scar in the response to damage and repair of the central nervous system. Cell Tissue Res, 2012. 349(1): p. 169-80.

23. Jessen, K.R. and R. Mirsky, The repair Schwann cell and its function in regenerating nerves. The Journal of physiology, 2016. 594(13): p. 3521-3531.

24. Dahlin, L.B., Chapter Seven - The Role of Timing in Nerve Reconstruction, in International Review of Neurobiology, S. Geuna, et al., Editors. 2013, Academic Press. p. 151-164.

25. Robinson, L.R., Traumatic injury to peripheral nerves. Muscle Nerve, 2000. 23(6): p. 863-73.

26. Ghasemi-Rad, M., et al., $A$ handy review of carpal tunnel syndrome: From anatomy to diagnosis and treatment. World journal of radiology, 2014. 6(6): p. 284-300.

27. Plastaras, C.T., A. Chhatre, and A.S. Kotcharian, Perioperative upper extremity peripheral nerve traction injuries. Orthop Clin North Am, 2014. 45(1): p. 47-53.

28. Won, J.C. and T.S. Park, Recent Advances in Diagnostic Strategies for Diabetic Peripheral Neuropathy. 2016. 31(2): p. 230-8.

29. Wojtkiewicz, D.M., et al., Social impact of peripheral nerve injuries. Hand (New York, N.Y.), 2015. 10(2): p. 161-167.

30. SEDDON, H.J., THREE TYPES OF NERVE INJURY. Brain, 1943. 66(4): p. 237-288.

31. Sunderland, S., A classification of peripheral nerve injuries producing loss of function. Brain, 1951. 74(4): p. 491-516.

32. DeFrancesco-Lisowitz, A., et al., The neuroimmunology of degeneration and regeneration in the peripheral nervous system. Neuroscience, 2015. 302: p. 174-203.

33. Kiryu-Seo, $\mathrm{S}$. and $\mathrm{H}$. Kiyama, The nuclear events guiding successful nerve regeneration. Front Mol Neurosci, 2011. 4: p. 53.

34. Conforti, L., J. Gilley, and M.P. Coleman, Wallerian degeneration: an emerging axon death pathway linking injury and disease. Nat Rev Neurosci, 2014. 15(6): p. 394-409.

35. Namgung, U., The role of Schwann cell-axon interaction in peripheral nerve regeneration. Cells Tissues Organs, 2014. 200(1): p. 6-12.

36. Jessen, K.R., R. Mirsky, and A.C. Lloyd, Schwann Cells: Development and Role in Nerve Repair. Cold Spring Harb Perspect Biol, 2015. 7(7): p. a020487. 
37. Chen, P., X. Piao, and P. Bonaldo, Role of macrophages in Wallerian degeneration and axonal regeneration after peripheral nerve injury. Acta Neuropathol, 2015. 130(5): $p$. 605-18.

38. Bearce, E.A., B. Erdogan, and L.A. Lowery, TIPsy tour guides: how microtubule plus-end tracking proteins (+TIPs) facilitate axon guidance. Front Cell Neurosci, 2015. 9: p. 241.

39. Steketee, M.B., et al., Regulation of intrinsic axon growth ability at retinal ganglion cell growth cones. Invest Ophthalmol Vis Sci, 2014. 55(7): p. 4369-77.

40. Fu, S.Y. and T. Gordon, The cellular and molecular basis of peripheral nerve regeneration. Mol Neurobiol, 1997. 14(1-2): p. 67-116.

41. Bhatheja, K. and J. Field, Schwann cells: Origins and role in axonal maintenance and regeneration. The International Journal of Biochemistry \& Cell Biology, 2006. 38(12): p. 1995-1999.

42. Jessen, K.R. and R. Mirsky, Negative regulation of myelination: relevance for development, injury, and demyelinating disease. Glia, 2008. 56(14): p. 1552-65.

43. Brushart, T.M., et al., Schwann cell phenotype is regulated by axon modality and central-peripheral location, and persists in vitro. Exp Neurol, 2013. 247: p. 272-81.

44. McKerracher, L., et al., Identification of myelin-associated glycoprotein as a major myelin-derived inhibitor of neurite growth. Neuron, 1994. 13(4): p. 805-11.

45. Namgung, U., The Role of Schwann Cell-Axon Interaction in Peripheral Nerve Regeneration. Vol. 200. 2015.

46. Arthur-Farraj, P.J., et al., c-Jun reprograms Schwann cells of injured nerves to generate a repair cell essential for regeneration. Neuron, 2012. 75(4): p. 633-47.

47. Dahlin, L.B., Techniques of peripheral nerve repair. Scand J Surg, 2008. 97(4): p. 310-6.

48. Dellon, E.S. and A.L. Dellon, The first nerve graft, Vulpian, and the nineteenth century neural regeneration controversy. J Hand Surg Am, 1993. 18(2): p. 369-72.

49. Isaacs, J., Treatment of acute peripheral nerve injuries: current concepts. J Hand Surg Am, 2010. 35(3): p. 491-7; quiz 498.

50. Suchyta, M.A., et al., Advances in peripheral nerve regeneration as it relates to VCA. Vascularized Composite Allotransplantation, 2016. 3(1-2): p. 75-88.

51. Fries, C.A., D.W. Tuder, and M.R. Davis, Preclinical Models in Vascularized Composite Allotransplantation. Current Transplantation Reports, 2015. 2(3): p. 284-289.

52. Vale, T.A., et al., Chronic non-freezing cold injury results in neuropathic pain due to a sensory neuropathy. Brain : a journal of neurology, 2017. 140(10): p. 2557-2569.

53. Archibald, S.J., et al., Monkey median nerve repaired by nerve graft or collagen nerve guide tube. J Neurosci, 1995. 15(5 Pt 2): p. 4109-23.

54. Lovati, A.B., et al., Nerve Repair Using Decellularized Nerve Grafts in Rat Models. A Review of the Literature. Frontiers in cellular neuroscience, 2018. 12: p. 427-427.

55. Gulati, A.K., Evaluation of acellular and cellular nerve grafts in repair of rat peripheral nerve. J Neurosurg, 1988. 68(1): p. 117-23.

56. Freytes, D.O., et al., Biaxial strength of multilaminated extracellular matrix scaffolds. Biomaterials, 2004. 25(12): p. 2353-61.

57. De Filippo, R.E., J.J. Yoo, and A. Atala, Urethral replacement using cell seeded tubularized collagen matrices. J Urol, 2002. 168(4 Pt 2): p. 1789-92; discussion 1792-3.

58. Woods, T. and P.F. Gratzer, Effectiveness of three extraction techniques in the development of a decellularized bone-anterior cruciate ligament-bone graft. Biomaterials, 2005. 26(35): p. 7339-49.

59. Gamba, P.G., et al., Experimental abdominal wall defect repaired with acellular matrix. Pediatr Surg Int, 2002. 18(5-6): p. 327-31.

60. Kim, B.S., J.J. Yoo, and A. Atala, Peripheral nerve regeneration using acellular nerve grafts. J Biomed Mater Res A, 2004. 68(2): p. 201-9. 
61. Lin, C.H., et al., In Vivo Performance of Decellularized Vascular Grafts: A Review Article. Int J Mol Sci, 2018. 19(7).

62. Wang, E.W., J. Zhang, and J.H. Huang, Repairing peripheral nerve injury using tissue engineering techniques. Neural regeneration research, 2015. 10(9): p. 1393-1394.

63. Chang, W., et al., Tissue-engineered spiral nerve guidance conduit for peripheral nerve regeneration. Acta Biomater, 2018. 73: p. 302-311.

64. Gonzalez-Perez, F., et al., Tubulization with chitosan guides for the repair of long gap peripheral nerve injury in the rat. Microsurgery, 2015. 35(4): p. 300-8.

65. Kehoe, S., X.F. Zhang, and D. Boyd, FDA approved guidance conduits and wraps for peripheral nerve injury: A review of materials and efficacy. Injury, 2012. 43(5): p. 553572.

66. de Ruiter, G.C.W., et al., Designing ideal conduits for peripheral nerve repair. Neurosurgical focus, 2009. 26(2): p. E5-E5.

67. Bueno, F.R. and S.B. Shah, Implications of tensile loading for the tissue engineering of nerves. Tissue Eng Part B Rev, 2008. 14(3): p. 219-33.

68. Gu, X., F. Ding, and D.F. Williams, Neural tissue engineering options for peripheral nerve regeneration. Biomaterials, 2014. 35(24): p. 6143-6156.

69. de Luca, A.C., et al., Extracellular matrix components in peripheral nerve repair: how to affect neural cellular response and nerve regeneration? Neural Regeneration Research, 2014. 9(22): p. 1943-1948.

70. Belanger, K., et al., A multi-layered nerve guidance conduit design adapted to facilitate surgical implantation. Health Science Reports, 2018. 1(12): p. e86.

71. Carvalho, C.R., et al., Tunable Enzymatically Cross-Linked Silk Fibroin Tubular Conduits for Guided Tissue Regeneration. Adv Healthc Mater, 2018. 7(17): p. e1800186.

72. Menorca, R.M.G., T.S. Fussell, and J.C. Elfar, Peripheral Nerve Trauma: Mechanisms of Injury and Recovery. Hand clinics, 2013. 29(3): p. 317-330.

73. Subramanian, A., U.M. Krishnan, and S. Sethuraman, Development of biomaterial scaffold for nerve tissue engineering: Biomaterial mediated neural regeneration. Journal of biomedical science, 2009. 16(1): p. 108-108.

74. Chen, Y.-S., et al., An in vivo evaluation of a biodegradable genipin-cross-linked gelatin peripheral nerve guide conduit material. Biomaterials, 2005. 26(18): p. 3911-3918.

75. Yang, Y., et al., Degradation behaviors of nerve guidance conduits made up of silk fibroin in vitro and in vivo. Polymer Degradation and Stability, 2009. 94(12): p. 22132220.

76. Wang, M.L., et al., Peripheral nerve injury, scarring, and recovery. Connective Tissue Research, 2019. 60(1): p. 3-9.

77. Huang, C., et al., Nerve Guidance Conduits from Aligned Nanofibers: Improvement of Nerve Regeneration through Longitudinal Nanogrooves on a Fiber Surface. ACS Applied Materials \& Interfaces, 2015. 7(13): p. 7189-7196.

78. Liu, C., et al., Incorporation and release of dual growth factors for nerve tissue engineering using nanofibrous bicomponent scaffolds. Biomedical Materials, 2018. 13(4): p. 044107.

79. Ruiter, G.C.W.d., et al., Designing ideal conduits for peripheral nerve repair. 2009. 26(2): p. E5.

80. Cattin, A.L., et al., Macrophage-Induced Blood Vessels Guide Schwann Cell-Mediated Regeneration of Peripheral Nerves. Cell, 2015. 162(5): p. 1127-39.

81. Zhao, Y.-H., et al., Novel conductive polypyrrole/silk fibroin scaffold for neural tissue repair. Neural Regeneration Research, 2018. 13(8): p. 1455-1464.

82. Muangsanit, P., R.J. Shipley, and J.B. Phillips, Vascularization Strategies for Peripheral Nerve Tissue Engineering. Anatomical record (Hoboken, N.J. : 2007), 2018. 301(10): p. 1657-1667. 
83. Giannessi, E., et al., An autologously generated platelet-rich plasma suturable membrane may enhance peripheral nerve regeneration after neurorraphy in an acute injury model of sciatic nerve neurotmesis. J Reconstr Microsurg, 2014. 30(9): p. 617-26.

84. Stang, F., G. Keilhoff, and H. Fansa, Biocompatibility of Different Nerve Tubes. Materials, 2009. 2(4): p. 1480.

85. Muheremu, A. and Q. Ao, Past, Present, and Future of Nerve Conduits in the Treatment of Peripheral Nerve Injury. BioMed research international, 2015. 2015: p. 237507237507.

86. Nardo, T., et al., Chapter 65 - Synthetic Biomaterial for Regenerative Medicine Applications, in Kidney Transplantation, Bioengineering and Regeneration, G. Orlando, G. Remuzzi, and D.F. Williams, Editors. 2017, Academic Press. p. 901-921.

87. Matsumine, H., et al., A polylactic acid non-woven nerve conduit for facial nerve regeneration in rats. Journal of Tissue Engineering and Regenerative Medicine, 2014. 8(6): p. 454-462.

88. Lu, M.C., et al., Evaluation of a multi-layer microbraided polylactic acid fiber-reinforced conduit for peripheral nerve regeneration. J Mater Sci Mater Med, 2009. 20(5): $p$. 1175-80.

89. Zeng, C.-G., et al., Fabrication and evaluation of PLLA multichannel conduits with nanofibrous microstructure for the differentiation of NSCs in vitro. Tissue engineering. Part A, 2014. 20(5-6): p. 1038-1048.

90. Rutkowski, G.E., et al., Synergistic effects of micropatterned biodegradable conduits and Schwann cells on sciatic nerve regeneration. J Neural Eng, 2004. 1(3): p. 151-7.

91. Shin, R.H., et al., Treatment of a segmental nerve defect in the rat with use of bioabsorbable synthetic nerve conduits: a comparison of commercially available conduits. J Bone Joint Surg Am, 2009. 91(9): p. 2194-204.

92. Navissano, M., et al., Neurotube ${ }^{\circledast}$ for facial nerve repair. Microsurgery, 2005. 25(4): p. 268-271.

93. Wu, T., et al., Laminin-coated nerve guidance conduits based on poly(I-lactide-coglycolide) fibers and yarns for promoting Schwann cells' proliferation and migration. Journal of Materials Chemistry B, 2017. 5(17): p. 3186-3194.

94. Labroo, P., et al., Novel drug delivering conduit for peripheral nerve regeneration. J Neural Eng, 2017. 14(6): p. 066011.

95. Lee, S.J., et al., Fabrication of a Highly Aligned Neural Scaffold via a Table Top Stereolithography 3D Printing and Electrospinning<sup/>. Tissue Eng Part A, 2017. 23(11-12): p. 491-502.

96. Kokai, L.E., A.M. Ghaznavi, and K.G. Marra, Incorporation of double-walled microspheres into polymer nerve guides for the sustained delivery of glial cell linederived neurotrophic factor. Biomaterials, 2010. 31(8): p. 2313-2322.

97. Hsu, S.-h., W.-C. Chang, and C.-T. Yen, Novel flexible nerve conduits made of waterbased biodegradable polyurethane for peripheral nerve regeneration. Journal of Biomedical Materials Research Part A, 2017. 105(5): p. 1383-1392.

98. Singh, A., et al., Aligned Chitosan-Gelatin Cryogel-Filled Polyurethane Nerve Guidance Channel for Neural Tissue Engineering: Fabrication, Characterization, and In Vitro Evaluation. Biomacromolecules, 2018.

99. Stocco, E., et al., Partially oxidized polyvinyl alcohol conduitfor peripheral nerve regeneration. Scientific reports, 2018. 8(1): p. 604-604.

100. Wan, H., et al., [Research about schwann cells and PLGA implanted to rat transected spinal cord]. Zhonghua Wai Ke Za Zhi, 2007. 45(12): p. 843-6. 
101. Peng, S.-W., et al., Nerve guidance conduit with a hybrid structure of a PLGA microfibrous bundle wrapped in a micro/nanostructured membrane. International journal of nanomedicine, 2017. 12: p. 421-432.

102. Liu, H., et al., Salidroside promotes peripheral nerve regeneration based on tissue engineering strategy using Schwann cells and PLGA: in vitro and in vivo. Sci Rep, 2017. 7: p. 39869.

103. Xu, F., et al., NECL1 coated PLGA as favorable conduits for repair of injured peripheral nerve. Materials Science and Engineering: C, 2017. 70: p. 1132-1140.

104. Tanir, T.E., et al., PCL and PCL-based materials in biomedical applications AU Malikmammadov, Elbay. Journal of Biomaterials Science, Polymer Edition, 2018. 29(79): p. 863-893.

105. Wang, W., et al., Assessment of PCL/carbon material scaffolds for bone regeneration. J Mech Behav Biomed Mater, 2019. 93: p. 52-60.

106. Fu, N., et al., PCL-PEG-PCL film promotes cartilage regeneration in vivo. Cell Prolif, 2016. 49(6): p. 729-739.

107. Bala Balakrishnan, P., et al., Star poly(c-caprolactone)-based electrospun fibers as biocompatible scaffold for doxorubicin with prolonged drug release activity. Colloids and Surfaces B: Biointerfaces, 2018. 161: p. 488-496.

108. Grossen, P., et al., PEG-PCL-based nanomedicines: A biodegradable drug delivery system and its application. J Control Release, 2017. 260: p. 46-60.

109. Pathak, V.M. and Navneet, Review on the current status of polymer degradation: a microbial approach. Bioresources and Bioprocessing, 2017. 4(1): p. 15.

110. Salmoria, G.V., et al., Development of PCL/Ibuprofen Tubes for Peripheral Nerve Regeneration. Procedia CIRP, 2016. 49: p. 193-198.

111. Mobasseri, A., et al., Polymer scaffolds with preferential parallel grooves enhance nerve regeneration. Tissue Eng Part A, 2015. 21(5-6): p. 1152-62.

112. Zhang, X.F., et al., Experimental composite guidance conduits for peripheral nerve repair: An evaluation of ion release. Materials Science and Engineering: C, 2012. 32(6): p. 1654-1663.

113. Jing, W., et al., Constructing conductive conduit with conductive fibrous infilling for peripheral nerve regeneration. Chemical Engineering Journal, 2018. 345: p. 566-577.

114. Sun, B., et al., Polypyrrole-coated poly(l-lactic acid-co-e-caprolactone)/silk fibroin nanofibrous nerve guidance conduit induced nerve regeneration in rat. Materials Science and Engineering: C, 2019. 94: p. 190-199.

115. Du, J., et al., Biomimetic neural scaffolds: a crucial step towards optimal peripheral nerve regeneration. Biomaterials science, 2018. 6(6): p. 1299-1311.

116. Pfister, L.A., et al., Hydrogel nerve conduits produced from alginate/chitosan complexes. Journal of Biomedical Materials Research Part A, 2007. 80A(4): p. 932-937.

117. Wang, Z.Z. and S.E. Sakiyama-Elbert, Matrices, scaffolds \& carriers for cell delivery in nerve regeneration. Experimental Neurology, 2018.

118. Resch, A., et al., Co-Culturing Human Adipose Derived Stem Cells and Schwann Cells on Spider Silk-A New Approach as Prerequisite for Enhanced Nerve Regeneration. Int J Mol Sci, 2018. 20(1).

119. Wang, C., et al., Silk fibroin enhances peripheral nerve regeneration by improving vascularization within nerve conduits. J Biomed Mater Res A, 2018. 106(7): p. 20702077.

120. Yang, Y., et al., Development and evaluation of silk fibroin-based nerve grafts used for peripheral nerve regeneration. Biomaterials, 2007. 28(36): p. 5526-35.

121. Das, S., et al., In vivo studies of silk based gold nano-composite conduits for functional peripheral nerve regeneration. Biomaterials, 2015. 62: p. 66-75. 
122. Sierpinski, P., et al., The use of keratin biomaterials derived from human hair for the promotion of rapid regeneration of peripheral nerves. Biomaterials, 2008. 29(1): $p$. 118-128.

123. Pace, L.A., et al., A human hair keratin hydrogel scaffold enhances median nerve regeneration in nonhuman primates: an electrophysiological and histological study. Tissue Eng Part A, 2014. 20(3-4): p. 507-17.

124. Lin, Y.C., et al., Keratin gel filler for peripheral nerve repair in a rodent sciatic nerve injury model. Plast Reconstr Surg, 2012. 129(1): p. 67-78.

125. Meyer, C., et al., Chitosan-film enhanced chitosan nerve guides for long-distance regeneration of peripheral nerves. Biomaterials, 2016. 76: p. 33-51.

126. Moattari, M., et al., Chitosan-film associated with mesenchymal stem cells enhanced regeneration of peripheral nerves: A rat sciatic nerve model. J Chem Neuroanat, 2018. 88: p. 46-54.

127. Carvalho, C.R., et al., Investigation of cell adhesion in chitosan membranes for peripheral nerve regeneration. Mater Sci Eng C Mater Biol Appl, 2017. 71: p. 11221134.

128. Lin, S.C.-Y., et al., Production and in vitro evaluation of macroporous, cell-encapsulating alginate fibres for nerve repair. Materials Science and Engineering: C, 2017. 73: p. 653664.

129. Sarker, M.D., et al., Bio-fabrication of peptide-modified alginate scaffolds: Printability, mechanical stability and neurite outgrowth assessments. Bioprinting, 2019: p. e00045.

130. Mondal, M., The silk proteins, sericin and fibroin in silkworm, Bombyx mori Linn., - a review. Caspian Journal of Environmental Sciences, 2007. 5(2): p. 63-76.

131. Jastrzebska, K., et al., Silk as an innovative biomaterial for cancer therapy. Reports of Practical Oncology \& Radiotherapy, 2015. 20(2): p. 87-98.

132. Vepari, C. and D.L. Kaplan, Silk as a Biomaterial. Progress in polymer science, 2007. 32(8-9): p. 991-1007.

133. Costa, J.B., et al., Fast Setting Silk Fibroin Bioink for Bioprinting of Patient-Specific Memory-Shape Implants. Adv Healthc Mater, 2017. 6(22).

134. Ribeiro, V.P., et al., Rapidly responsive silk fibroin hydrogels as an artificial matrix for the programmed tumor cells death. PLoS One, 2018. 13(4): p. e0194441.

135. Carvalho, M.R., et al., Microfluidics: Tuning Enzymatically Crosslinked Silk Fibroin Hydrogel Properties for the Development of a Colorectal Cancer Extravasation 3D Model on a Chip (Global Challenges 5-6/2018). Global Challenges, 2018. 2(5-6): p. 1870164.

136. Dinis, T.M., et al., 3D multi-channel bi-functionalized silk electrospun conduits for peripheral nerve regeneration. Journal of the Mechanical Behavior of Biomedical Materials, 2015. 41: p. 43-55.

137. Ng, K.W., Human hair keratin templates for biomedical applications. Frontiers in Bioengineering and Biotechnology.

138. Ko, J., et al., Human Hair Keratin for Biocompatible Flexible and Transient Electronic Devices. ACS Applied Materials \& Interfaces, 2017. 9(49): p. 43004-43012.

139. Yue, K., et al., Visible light crosslinkable human hair keratin hydrogels. Bioengineering \& translational medicine, 2018. 3(1): p. 37-48.

140. Lee, H., et al., Human hair keratin and its-based biomaterials for biomedical applications. Tissue Engineering and Regenerative Medicine, 2014. 11(4): p. 255-265.

141. Apel, P.J., et al., Peripheral nerve regeneration using a keratin-based scaffold: longterm functional and histological outcomes in a mouse model. J Hand Surg Am, 2008. 33(9): p. 1541-7. 
142. Bak, M., et al., The role of chitin and chitosan in peripheral nerve reconstruction. Polim Med, 2017. 47(1): p. 43-47.

143. Muzzarelli, R.A.A., CHAPTER 1 - ENZYMIC SYNTHESIS OF CHITIN AND CHITOSAN, in Chitin, R.A.A. Muzzarelli, Editor. 1977, Pergamon. p. 5-44.

144. Rinaudo, M., Chitin and chitosan: Properties and applications. Progress in Polymer Science, 2006. 31(7): p. 603-632.

145. Freier, T., et al., Chitin-based tubes for tissue engineering in the nervous system. Biomaterials, 2005. 26(22): p. 4624-32.

146. Martin-Lopez, E., M. Nieto-Diaz, and M. Nieto-Sampedro, Differential adhesiveness and neurite-promoting activity for neural cells of chitosan, gelatin, and poly-L-lysine films. J Biomater Appl, 2012. 26(7): p. 791-809.

147. Wenling, C., et al., Effects of the degree of deacetylation on the physicochemical properties and Schwann cell affinity of chitosan films. J Biomater Appl, 2005. 20(2): p. 157-77.

148. Wrobel, S., et al., In vitro evaluation of cell-seeded chitosan films for peripheral nerve tissue engineering. Tissue Eng Part A, 2014. 20(17-18): p. 2339-49.

149. Cooper, A., N. Bhattarai, and M. Zhang, Fabrication and cellular compatibility of aligned chitosan-PCL fibers for nerve tissue regeneration. Carbohydrate Polymers, 2011. 85(1): p. 149-156.

150. Gnavi, S., et al., In vitro evaluation of gelatin and chitosan electrospun fibres as an artificial guide in peripheral nerve repair: a comparative study. Journal of Tissue Engineering and Regenerative Medicine, 2018. 12(2): p. e679-e694.

151. Wang, W., et al., Effects of Schwann cell alignment along the oriented electrospun chitosan nanofibers on nerve regeneration. J Biomed Mater Res A, 2009. 91(4): p. 9941005.

152. Haastert-Talini, K., et al., Chitosan tubes of varying degrees of acetylation for bridging peripheral nerve defects. Biomaterials, 2013. 34(38): p. 9886-904.

153. Stenberg, L., et al., Nerve regeneration in chitosan conduits and in autologous nerve grafts in healthy and in type 2 diabetic Goto-Kakizaki rats. Eur J Neurosci, 2016. 43(3): p. 463-73.

154. Lee, K.Y. and D.J. Mooney, Alginate: properties and biomedical applications. Progress in polymer science, 2012. 37(1): p. 106-126.

155. Suzuki, Y., et al., In vivo evaluation of a novel alginate dressing. J Biomed Mater Res, 1999. 48(4): p. 522-7.

156. Ochbaum, G., M. Davidovich-Pinhas, and R. Bitton, Tuning the mechanical properties of alginate-peptide hydrogels. Soft Matter, 2018. 14(21): p. 4364-4373.

157. Suzuki, Y., et al., Cat peripheral nerve regeneration across $50 \mathrm{~mm}$ gap repaired with a novel nerve guide composed of freeze-dried alginate gel. Neurosci Lett, 1999. 259(2): p. 75-8.

158. Hashimoto, T., et al., Peripheral nerve regeneration through alginate gel: analysis of early outgrowth and late increase in diameter of regenerating axons. Experimental Brain Research, 2002. 146(3): p. 356-368.

159. Quigley, A.F., et al., Engineering a multimodal nerve conduit for repair of injured peripheral nerve. J Neural Eng, 2013. 10(1): p. 016008.

160. Naghieh, S., et al., Indirect 3D bioprinting and characterization of alginate scaffolds for potential nerve tissue engineering applications. Journal of the Mechanical Behavior of Biomedical Materials, 2019. 93: p. 183-193.

161. Wu, H., et al., Establishment of nerve growth factor gradients on aligned chitosanpolylactide /alginate fibers for neural tissue engineering applications. Colloids and Surfaces B: Biointerfaces, 2017. 160: p. 598-609. 
162. de Luca, A.C., et al., Extracellular matrix components in peripheral nerve repair: how to affect neural cellular response and nerve regeneration? Neural Regen Res, 2014. 9(22): p. 1943-8.

163. Klein, S., et al., Differential Effects of Coating Materials on Viability and Migration of Schwann Cells. Materials (Basel, Switzerland), 2016. 9(3): p. 150.

164. Fujimaki, H., et al., Oriented collagen tubes combined with basic fibroblast growth factor promote peripheral nerve regeneration in a $15 \mathrm{~mm}$ sciatic nerve defect rat model. J Biomed Mater Res A, 2017. 105(1): p. 8-14.

165. Huang, L., et al., A compound scaffold with uniform longitudinally oriented guidance cues and a porous sheath promotes peripheral nerve regeneration in vivo. Acta Biomaterialia, 2018. 68: p. 223-236.

166. Bhandari, P.S., Use of fibrin glue in the repair of brachial plexus and peripheral nerve injuries. The Indian Journal of Neurotrauma, 2013. 10(1): p. 30-32.

167. Reichenberger, M.A., et al., ADSCs in a fibrin matrix enhance nerve regeneration after epineural suturing in a rat model. Microsurgery, 2016. 36(6): p. 491-500.

168. Du, J., et al., Prompt peripheral nerve regeneration induced by a hierarchically aligned fibrin nanofiber hydrogel. Acta Biomater, 2017. 55: p. 296-309.

169. Mosahebi, A., M. Wiberg, and G. Terenghi, Addition of fibronectin to alginate matrix improves peripheral nerve regeneration in tissue-engineered conduits. Tissue Eng, 2003. 9(2): p. 209-18.

170. Gonzalez-Perez, F., et al., Stabilization, Rolling, and Addition of Other Extracellular Matrix Proteins to Collagen Hydrogels Improve Regeneration in Chitosan Guides for Long Peripheral Nerve Gaps in Rats. Neurosurgery, 2017. 80(3): p. 465-474.

171. Kijeńska, E., et al., Interaction of Schwann cells with laminin encapsulated PLCL coreshell nanofibers for nerve tissue engineering. European Polymer Journal, 2014. 50: p. 30-38.

172. Haggerty, A.E., et al., Laminin polymer treatment accelerates repair of the crushed peripheral nerve in adult rats. Acta Biomaterialia, 2019. 86: p. 185-193.

173. Entekhabi, E., et al., Design and manufacture of neural tissue engineering scaffolds using hyaluronic acid and polycaprolactone nanofibers with controlled porosity. Materials Science and Engineering: C, 2016. 69: p. 380-387.

174. Vilariño-Feltrer, G., et al., Schwann-cell cylinders grown inside hyaluronic-acid tubular scaffolds with gradient porosity. Acta Biomaterialia, 2016. 30: p. 199-211.

175. Khan, R. and M.H. Khan, Use of collagen as a biomaterial: An update. Journal of Indian Society of Periodontology, 2013. 17(4): p. 539-542.

176. Silva, T.H., et al., Marine origin collagens and its potential applications. Marine drugs, 2014. 12(12): p. 5881-5901.

177. Dong, C. and Y. Lv, Application of Collagen Scaffold in Tissue Engineering: Recent Advances and New Perspectives. Polymers, 2016. 8(2): p. 42.

178. Bozkurt, A., et al., Clinical and biometrical 12-month follow-up in patients after reconstruction of the sural nerve biopsy defect by the collagen-based nerve guide Neuromaix. Eur J Med Res, 2017. 22(1): p. 34.

179. Litvinov, R.I. and J.W. Weisel, What Is the Biological and Clinical Relevance of Fibrin? Seminars in thrombosis and hemostasis, 2016. 42(4): p. 333-343.

180. Esposito, F., et al., Fibrin Sealants in Dura Sealing: A Systematic Literature Review. PloS one, 2016. 11(4): p. e0151533-e0151533.

181. Olcucuoglu, E., et al., Fibrin sealant effects on the ilioinguinal nerve. J Invest Surg, 2011. 24(6): p. 267-72.

182. Pankov, R. and K.M. Yamada, Fibronectin at a glance. Journal of Cell Science, 2002. 115(20): p. 3861-3863. 
183. Whitworth, I.H., et al., Orientated mats of fibronectin as a conduit material for use in peripheral nerve repair. The Journal of Hand Surgery: British \& European Volume, 1995. 20(4): p. 429-436.

184. Chen, Y.S., et al., Peripheral nerve regeneration using silicone rubber chambers filled with collagen, laminin and fibronectin. Biomaterials, 2000. 21(15): p. 1541-7.

185. Liang, S. and K.A. Crutcher, Neuronal migration on laminin in vitro. Brain Res Dev Brain Res, 1992. 66(1): p. 127-32.

186. Adams, D.N., et al., Growth cones turn and migrate up an immobilized gradient of the laminin IKVAV peptide. J Neurobiol, 2005. 62(1): p. 134-47.

187. Zhang, X.F., et al., Laminin-modified and aligned poly(3-hydroxybutyrate-co-3hydroxyvalerate)/polyethylene oxide nanofibrous nerve conduits promote peripheral nerve regeneration. J Tissue Eng Regen Med, 2018. 12(1): p. e627-e636.

188. Swindle-Reilly, K.E., et al., The impact of laminin on 3D neurite extension in collagen gels. J Neural Eng, 2012. 9(4): p. 046007.

189. Zamboni, F., et al., The potential of hyaluronic acid in immunoprotection and immunomodulation: Chemistry, processing and function. Progress in Materials Science, 2018. 97: p. 97-122.

190. Chircov, C., A.M. Grumezescu, and L.E. Bejenaru, Hyaluronic acid-based scaffolds for tissue engineering. Rom J Morphol Embryol, 2018. 59(1): p. 71-76.

191. Huang, L., et al., Local injection of high-molecular hyaluronan promotes wound healing in old rats by increasing angiogenesis. Oncotarget, 2017. 9(9): p. 8241-8252.

192. Wang, K.K., et al., Hyaluronic acid enhances peripheral nerve regeneration in vivo. Microsurgery, 1998. 18(4): p. 270-5.

193. Ikeda, K., et al., Hyaluronic acid prevents peripheral nerve adhesion. British Journal of Plastic Surgery, 2003. 56(4): p. 342-347.

194. Murphy, S.V. and A. Atala, 3D bioprinting of tissues and organs. Nat Biotechnol, 2014. 32(8): p. 773-85.

195. Hamburg, M.A. and F.S. Collins, The path to personalized medicine. N Engl J Med, 2010. 363(4): p. 301-4.

196. Rengier, F., et al., 3D printing based on imaging data: review of medical applications. Int J Comput Assist Radiol Surg, 2010. 5(4): p. 335-41.

197. Schmidt, C.E. and J.B. Leach, Neural tissue engineering: strategies for repair and regeneration. Annu Rev Biomed Eng, 2003. 5: p. 293-347.

198. Ji, X.M., et al., Novel miRNA, miR-sc14, promotes Schwann cell proliferation and migration. Neural Regen Res, 2019. 14(9): p. 1651-1656.

199. Petcu, E.B., et al., 3D printing strategies for peripheral nerve regeneration. Biofabrication, 2018. 10(3): p. 032001.

200. Johnson, B.N., et al., 3D Printed Anatomical Nerve Regeneration Pathways. Advanced Functional Materials, 2015. 25(39): p. 6205-6217.

201. Hu, Y., et al., 3D-engineering of Cellularized Conduits for Peripheral Nerve Regeneration. Scientific Reports, 2016. 6: p. 32184.

202. Tao, J., et al., Rapid 3D printing of functional nanoparticle-enhanced conduits for effective nerve repair. Acta Biomaterialia, 2019. 90: p. 49-59.

203. Zhong, Y., et al., Three-dimensional Reconstruction of Peripheral Nerve Internal Fascicular Groups. Scientific reports, 2015. 5: p. 17168-17168. 